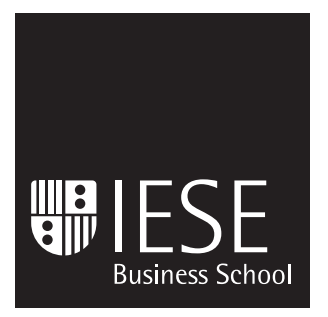

University of Navarra
Working Paper

WP no 651

September, 2006

\title{
CURRENT ACCOUNTS IN THE EURO AREA: AN INTERTEMPORAL APPROACH
}

\author{
José Manuel Campa
}

Angel Gavilán 
The CIIF, International Center for Financial Research, is an interdisciplinary center with an international outlook and a focus on teaching and research in finance. It was created at the beginning of 1992 to channel the financial research interests of a multidisciplinary group of professors at IESE Business School and has established itself as a nucleus of study within the School's activities.

Ten years on, our chief objectives remain the same:

- Find answers to the questions that confront the owners and managers of finance companies and the financial directors of all kinds of companies in the performance of their duties

- Develop new tools for financial management

- Study in depth the changes that occur in the market and their effects on the financial dimension of business activity

All of these activities are programmed and carried out with the support of our sponsoring companies. Apart from providing vital financial assistance, our sponsors also help to define the Center's research projects, ensuring their practical relevance.

The companies in question, to which we reiterate our thanks, are:

Aena, A.T. Kearney, Caja Madrid, Fundación Ramón Areces, Grupo Endesa, Royal Bank of Scotland and Unión Fenosa.

http://www.iese.edu/ciif/ 


\title{
CURRENT ACCOUNTS IN THE EURO AREA: AN INTERTEMPORAL APPROACH
}

\author{
José Manuel Campa* \\ Angel Gavilán**
}

\section{Abstract}

This paper uses an intertemporal model of the current account to evaluate the fluctuations in current account balances experienced by Euro area countries over the last three decades. In the model current account balances are used to smooth consumption and they are driven by expectations about future income and relative prices. This simple model is not rejected for six (Belgium, France, Italy, Netherlands, Portugal, and Spain) of the ten Euro area countries examined, although the model tends to underestimate their current account volatility. The analysis also shows that the relative contributions to current account balances of future output and relative prices differ across countries. Expectations of future growth increased in all Southern European countries at the creation of the Euro but they had considerably diverged by 2005. While in Portugal these expectations are now below its historical mean, in Spain they are at a historical high.

* Professor of Financial Management, Grupo Santander Chair in Financial Institutions, IESE

** Servicio de Estudios Banco de España

Keywords: Current account, euro, external deficits, economic integration. 


\section{CURRENT ACCOUNTS IN THE EURO AREA: AN INTERTEMPORAL APPROACH}

\section{Introduction}

Over the last few years, the current account in the Euro area, as a whole, has remained essentially balanced, with small deficits and surpluses very rarely above 1\% of GDP. This balance at the aggregate level hides the remarkably different evolution of the current account balances across member countries. Greece, Portugal and Spain, that presented almost balanced (or even in surplus) current accounts around the middle of the 1990s, have experienced since then almost continuously increasing current account deficits. In 2005, these imbalances were around 7\% of GDP in Greece, 9\% in Portugal and 8\% in Spain. In contrast, Germany has moved almost monotonically from current account deficits of about 1\% of its GDP in the last years of the 1990s to an external surplus above $4 \%$ in 2005. In a somehow similar process, Austria, that had been increasing its external deficits during the first half of the 1990s (reaching a deficit above 3\% of its GDP in 1999), has reverted that trend after the introduction of the Euro and has reduced its deficits monotonically to reach a small surplus in $2004 .{ }^{1}$ Whether these patterns of adjustment of current account balances within the area are a symptom of the success of the Euro or a sign for concern is at the centre of much controversy today.

These patterns in the current account can be seen, at least partly, as a natural consequence of the creation of the EMU and its implications in terms of a much higher degree of financial and economic integration among its member countries. In an open economy a country's external balance is determined by the interplay between the country's expectations of future income (relative to those of its trading partners) and the costs of the necessary borrowing or lending that the country has to engage in with the purpose of smoothing its consumption over time. Countries with higher expectations of future income will borrow today and run large current account deficits, while countries with lower expectations of future income will run current account surpluses. A higher degree of economic and financial integration exacerbates these patterns through two mechanisms. First, it reduces the costs of borrowing and lending internationally. ${ }^{2}$ And second, it induces competition across countries and fosters the elimination of internal inefficiencies and thus growth, what is especially relevant in low income countries which, in principle, have more inefficiency to eliminate.

\footnotetext{
${ }^{1}$ Data come from the OECD Economic Outlook.

2 This has been especially clear for EMU countries where currency risk has completely disappeared in interest rate spreads across countries and the growth in monetary and fixed income markets has been substantial.
} 
The EMU has followed, at least partly, this textbook prediction about the effects on current account balances of increased integration. Rich countries, like Germany, have been experiencing large and increasing external surpluses while poorer countries (like Spain, Greece or Portugal) has been experiencing large and increasing external deficits. Blanchard and Giavazzi (2002) provide more empirical evidence supporting this connection between integration and current account. Namely, for different sets of countries, they find that a higher degree of economic and financial integration is associated with more dispersion in the current account balances across countries and with a stronger positive correlation between income and current account balance.

The existing evidence, however, does not provide any information about the size of the current account fluctuations that the member countries should experience when adjusting to the new scenario. Thus, it is not clear whether the observed fluctuations reflect a proper adjustment by the countries or instead an over- or under-adjustment. In this sense, if some countries have increased their external indebtedness based on over-optimistic expectations about its future growth or about the positive effects that international integration would have on it (as pointed out by Gourinchas [2002]), they should experience a painful adjustment sooner or later. The decrease in economic activity experienced in recent years by some of the countries with large previous deficits, such as Portugal, seems to give support to the over-adjustment hypothesis.

The purpose of this paper is to answer the question of whether current account fluctuations in the Euro area are within what should be considered reasonable or have surpassed the reasonable boundaries. A precise answer to this question requires a specific model to determine what such a 'reasonable benchmark' for current account balances should be and to what extent existing current account balances are deviating from it. The current paper uses a standard intertemporal current account model as such a benchmark. The model considers a small open economy where consumers smooth consumption over time (Campbell, 1987). Thus, optimal consumption is based on the expectations of future output and relative prices, and current account balances in every period are the difference between optimal consumption and net output in that period. The model considers time-varying interest rates and exchange rates (through the existence of traded and no traded goods), a feature which could be potentially important in the context of the Euro area.

This model is confronted with the data over the last three decades for ten Euro area member countries. The model cannot be rejected to fit the behavior of the current account for six of them: Belgium, France, Italy, Netherlands, Portugal and Spain. The model is, however, rejected for Austria, Finland, Germany and Ireland. For these countries, the intertemporal approach pursued in the paper is not a valid representation of the data. For the six countries in which the model is not rejected, the paper then uses the model in three dimensions. First, it compares the current account predictions of the model with the actual ones. On average, the current account predicted by the model was only $60 \%, 80 \%$ and $77 \%$ of the actual current account of Netherlands, Portugal and Spain, respectively, and it was about 50\% less volatile than the actual one. For France and Italy, however, the model fitted almost perfectly both the level and the volatility of the current account fluctuations. Finally, the model overestimated considerably both the level and the volatility of the current account in Belgium.

Second, the paper analyses the main determinant for each country, of the current account predicted by the model. In the model, current account deficits occur for a combination of (i) expectations of higher future output relative to current output, and/or (ii) lower expected 
relative prices in the future (either via lower real interest rates or lower prices of traded goods relative to no traded goods). The relative contribution of these two components varies substantially across countries. For France, Italy and Netherlands current account balances are primarily driven by changes in expected future relative prices. In contrast, for Belgium, Portugal and Spain expected changes in net output are the primary driver of the current account (60\%, 85\% and 58\%, respectively).

Third, this paper takes a quick look at the expectations of future growth that, according to the model, are behind each country's external balance. This exercise points to some interesting facts. In the second half of the 1990s countries in southern Europe (France, Italy, Portugal and Spain) experienced increases in their expectations of future output. After a small correction around 2001, these expectations stabilized for Italy, continued to decline for Portugal, and started to increase again for France and Spain. At this point Spanish expectations of future output relative to current output are at their highest value of the last thirty years. Assuming that in the future the shares of investment and government expenditure to GDP remain at their actual levels in Spain, these expectations would imply a growth in per capita GDP for the next ten years $20 \%$ higher than the historical average of the past three decades.

The rest of the paper is organized as follows. Section 2 briefly reports some existing evidence on the connection between current account balances and economic and financial integration, and some evidence suggesting the possibility of current account over-adjustment in Portugal. Then, section 3 describes the intertemporal current account model used in this paper and its testable implications. These implications are tested in section 5 using the data described in section 4. For the countries in which the model can not be rejected, section 6 provides more detailed estimation results and additional implications of the model. Section 7 discusses different issues related to the validity of the model and section 8 concludes.

\section{The impact of international market integration on external balances}

There has recently been an increasing interest in understanding the process of current account adjustments. This interest has been partly due to the increase in current account deficits in some large economies, mainly the United States, coupled with the ongoing interest in large current account reversals. Most of this literature has focused on two related questions: the relationship between international financial and economic integration and current account balances, and the process and the determinants associated with large current account reversals.

Blanchard and Giavazzi (2002) is one example of the literature studying the first question. They consider two different time periods related to lower and higher degrees of economic integration (1985-1993 and 1994-2001) and show, for three different sets of countries (a subset of OECD countries, EU member countries and EMU member countries), that a country's average output per capita and its external balance relative to GDP are positively correlated in both periods. Under the standard assumption in neoclassical growth models that low income countries have higher growth potential than higher income countries, this evidence is consistent with the consumption smoothing hypothesis. More interestingly, they also show that the absolute value of this correlation increased from the earlier period to the later one as it will be predicted by an increase in economic integration. 
Figure 1 shows, that this result also holds true for the subsample of Euro area member countries when more recent years are included. ${ }^{3}$ The top figure shows the relationship between GDP per capita and cumulative current account balances for the period 1985-94 for the Euro area countries. The bottom chart shows the same relationship for the following decade 1995-04, which includes the impact of the creation of the Euro. In both cases, a positive relationship exists between GDP per capita and current account balances. This relationship is also more pronounced in the second period, with the Euro, than in the first period.

An increase in economic integration also implies that countries will be able to support larger external deficits relative to their GDPs. Blanchard and Giavazzi (2002) show that, consistent with this implication, the standard deviation of the current account balances relative to GDP across the countries in their three different sets of countries increased almost monotonically over the period 1975-2000 in which international economic integration also increased. As illustrated in Figure 2, this result also holds true after adding more recent years to the analysis. Despite a small decrease around 2000, the dispersion of current account balances has broadly increased over time following the increase in international integration.

Adalet and Eichengreen (2005) document a similar evidence. In particular, they report that the average current account balances in absolute value have been larger during historical periods of high capital mobility (Gold Standard [1870-1913], 3.7\% of GDP, the first part of the interwar period [1919-1926], 3.9\%, and the latter part of the last century [1973-2000], 4.8\%) than during periods of lower capital mobility (the Great Depression and the period 1960-1972, prior to the breakdown of Bretton Woods, in both cases below 2\%).

The second line of the research has been focused on how large current account imbalances get reversed. For industrial countries, the existing evidence indicates that current account reversals tend to occur around 5 percent of GDP, and involve a depreciation of the currency and a decrease in GDP growth (Freund and Warnock (2005), Debelle and Galati (2005) and IMF (2002)). Freund and Warnock (2005) also report that the depreciations associated to current account reversals are larger when the previous current account deficits have coincided with a surge in consumption rather than in investment.

It is not clear, however, that the previous evidence is directly applicable to the EMU member countries. In short, none of the current account reversals analyzed in the previous studies were suffered by a country belonging to a monetary union. This is relevant because the adjustment mechanisms are clearly limited for these countries. In particular, nominal exchange rate adjustment is not possible within a currency union and real exchange rate depreciation must come through inflation differentials. An exception to this comment is Edwards (2006), that provides some evidence on the likelihood of a current account reversal within a monetary union. He finds that belonging to a currency union does not lower the probability of facing a current account reversal or a sudden stop in foreign capital inflows. One important limitation of this evidence is that it refers mainly to very small countries and it is not clear that its conclusions are readily applicable to the EMU member countries.

More relevant evidence on current adjustments in the Euro area is now coming from Portugal. As mentioned in the Introduction, Portugal experienced in the second half of the 1990s large and persistent external deficits. These large deficits occurred jointly with increases in consumption and government spending that, coupled with a lack of productivity improvements,

\footnotetext{
${ }^{3}$ The same is true for the sets of OECD countries and EU member countries considered in Blanchard and Giavazzi (2002).
} 
made Portuguese inflation larger than the Euro area average. Low productivity growth and poor performance of their traded goods sector then led Portugal to a decrease in future growth expectations. As a consequence, Portugal is currently suffering a period of very low GDP growth (it grew at an average rate of 0.6\% per year during the period 2001-2005), increasing unemployment (unemployment increased by $85.4 \%$ in the same period) while still maintaining large current account deficits (in average accounting for 7.53\% of GDP). ${ }^{4}$

The case of Spain also deserves some attention. In 2005, the current account deficit reached an all time high around 8\% of GDP. At the same time, productivity growth in Spain is one of the lowest in the EMU. According to the OECD Productivity Index, Spanish productivity has only improved by $2.1 \%$ over the period 1999-2005. A very poor performance compared to the 3.7\% of the EMU average, but even worse if compared to some of the very good performers like Greece (22.3\%) or Ireland (17.3\%). In addition, during the same period, Spanish growth in nominal wages and unit labor costs has almost doubled that of the EMU (around 20\% for Spain vs. around 10\% for the EMU) and average annual inflation rate for Spain is 3.1\% (2.1\% in the EMU). As a consequence, Spanish real exchange rate has appreciated substantially (between $10 \%$ and 30\% depending on the measure).

\section{An intertemporal model of the current account}

As mentioned above, the main goal of this paper is to determine a benchmark scenario for the behavior of the current account that can be compared with the evolution of the current account balances in the data. For that purpose, we consider the model developed in Bergin and Sheffrin (2000) that belongs to the class of intertemporal current account (ICA) models. These models, first introduced by Sachs (1981), have been extensively used in the literature and basically constitute an extension of the permanent income hypothesis model to a small open economy. ${ }^{5}$ The underlying determinant of a country's current account in these models is their citizens' desire to smooth consumption over time.

The most salient feature of the model developed in Bergin and Sheffrin (2000) is that it allows simultaneously for time-varying interest rates and exchanges rates. They show that the inclusion of these features improves the traditionally poor empirical fit of simpler ICA models that, either do not incorporate exchange rates, or impose constant interest rates. This feature is also especially relevant for the analysis of current account fluctuations in the Euro area countries. The Euro has played an obvious role in fixing nominal exchange rates among member countries but it has also caused a significant change in the average level of interest rates in many of the member countries. These changes in interest rates and exchange rates are likely to have affected the evolution of the current account and, therefore, ought to be modelled explicitly.

The model considers a small open economy that can borrow and lend with the rest of the world at a time-varying real interest rate. There are two goods: traded and no traded goods. Consumption and borrowing decisions in the small open economy are taken by a representative

\footnotetext{
${ }^{4}$ See Blanchard (2006) for a more detailed description of the current Portuguese situation.

${ }^{5}$ Some examples are Sheffrin and Woo (1990), Otto (1992), Glick and Rogoff (1995), Ghosh (1995), Iscan (2002), Gruber (2004) and Nason and Rogers (2006).
} 
household who maximizes its discounted life time utility solving the following intertemporal maximization problem:

$$
\begin{aligned}
& \max E_{0} \sum_{t=0}^{\infty} \beta^{t} U\left(C_{T t}, C_{N t}\right) \\
& \text { s.t. } Y_{t}-\left(C_{T t}+P_{t} C_{N t}\right)-I_{t}-G_{t}+r_{t} B_{t-1}=B_{t}-B_{t-1} \quad \forall t
\end{aligned}
$$

where $C_{T t}$ and $C_{N t}$ denotes consumption by the household in traded and no traded goods, $P_{t}$ is the price of no traded goods in terms of traded goods, $Y_{t}$ denotes the value of current output, $I_{t}$ is investment expenditure, $G_{t}$ is government expenditure, $B_{t}$ is the stock of foreign assets at the beginning of the period, and $r_{t}$ is the net world real interest rate the country faces in terms of traded goods. ${ }^{6}$ Moreover, assume that per period utility function takes the following CobbDouglas form:

$$
U\left(C_{T t}, C_{N t}\right)=\frac{1}{1-\sigma}\left(C_{T t}^{a} C_{N t}^{1-a}\right)^{1-\sigma}
$$

Where $a \in(0,1)$ is, in equilibrium, the share of consumption of traded goods in total consumption and $\sigma>0$ is the inverse of the intertemporal elasticity of substitution.

The Euler equation for this maximization problem can be written as: ${ }^{7}$

$$
1=E_{t}\left[\beta^{\gamma}\left(1+r_{t+1}\right)^{\gamma}\left(\frac{C_{t}}{C_{t+1}}\right)\left(\frac{P_{t}}{P_{t+1}}\right)^{(1-a)(\gamma-1)}\right]
$$

where $C_{t}=C_{T t}+P_{t} C_{N t}$ denotes total consumption expenditure in terms of traded goods and $\gamma=\frac{1}{\sigma}$ is the intertemporal elasticity of substitution. Under certain conditions, Bergin and Sheffrin (2000) show that (2) can be written in a more tractable form as: ${ }^{8}$

$$
E_{t} \Delta c_{t+1}=\gamma E_{t} r_{t+1}^{*}
$$

where $\Delta c_{t}=\log C_{t+1}-\log C_{t}, r_{t}^{*}=r_{t}+\left[\frac{1-\gamma}{\gamma}(1-a)\right] \Delta p_{t}+$ constant

and $\Delta p_{t}=\log P_{t+1}-\log P_{t}$. Bergin and Sheffrin (2000) named $r_{t}^{*}$ the "consumption-based real interest rate" and we will use the same terminology here for simplicity. Basically, it is a weighted measure of relative prices, $r_{t}$ and $P_{t}{ }^{9}$

Equation (3) establishes the way in which relative prices affect the optimal consumption profile. In this model consumption change is not a zero-mean random-walk, a common feature of

\footnotetext{
${ }^{6}$ In this model, output, investment and government expenditure are exogenous.

${ }^{7}$ See Bergin and Sheffrin (2000) for the exact derivation.

${ }^{8}$ In particular, they assume joint log normality for the gross real world interest rate, the consumption growth rate and the percent change in the relative price of no traded goods, and that the variances and co variances between these variables are time invariant.

${ }^{9}$ The fact that $r_{t}^{*}$ is defined up to a constant will not be a problem for the empirical analysis below since all the relevant variables will be demeaned.
} 
many other models in this literature. Instead, expected changes in consumption are a function of the expected consumption-based real interest rate. Bergin and Sheffrin (2000) highlight the roles that the interest rate and the exchange rate have in the optimal consumption profile: ${ }^{10}$

- An increase in the real interest rate, $r_{t}$, makes current consumption more expensive relative to future consumption and induces substitution toward future consumption with elasticity $\gamma$.

- The exchange rate plays a similar role through the net impact of an intratemporal and an intertemporal effect. A change in the exchange rate induces an intratemporal substitution effect on consumption. When the price of traded goods is temporarily low households substitute traded goods for no traded goods in consumption. Given that the intratemporal rate of substitution is one (Cobb-Douglas), this raises the current consumption expenditure by (1-a). The intertemporal effect is driven by the relative price of future vs. current consumption in terms of the prices of traded goods. When the price of traded goods is temporarily high and expected to decrease, the future payment of a loan in terms of traded goods is high and also expected to decrease. This implies that this future repayment has a lower cost in terms of the full consumption bundle than in terms of traded goods alone. Thus $r_{t}^{*}$ rises and lowers the total consumption expenditure by the elasticity $\gamma(1-a)$. As long as $\gamma<1$, the intertemporal effect will dominate.

To conclude the solution of the maximization problem (1) one still needs to combine (3) with the intertemporal budget constraint of the problem. This is can be written as:

$$
\sum_{t=0}^{\infty} E_{0}\left(R_{t} C_{t}\right)=\sum_{t=0}^{\infty} E_{0}\left(R_{t} N O_{t}\right)+B_{0}
$$

where $N O_{t}=Y_{t}-I_{t}-G_{t}$ denotes the net output per period, $R_{t}=\frac{1}{\prod_{j=1}^{t}\left(1+r_{j}\right)}$

is the market discount rate for date $t$ consumption, and the transversal condition $\lim _{t \rightarrow \infty} E_{0}\left(R_{t} B_{t}\right)=0$ is assumed to be satisfied. Again, as for the Euler equation, Bergin and Sheffrin (2000) consider a more tractable expression for this intertemporal budget constraint and log-linearize (4) around the steady state in which $\bar{B}=0$ (that is, around the steady state where net foreign assets are 0). ${ }^{11}$ By doing this, they get that:

$$
-\sum_{t=1}^{\infty} \beta^{t}\left[\Delta n o_{t}-\Delta c_{t}\right]=n o_{0}-c_{0}
$$

where $\Delta n o_{t}=\log N O_{t+1}-\log N O_{t}, n o_{0}=\log N O_{0}$ and $c_{0}=\log C_{0}$.

\footnotetext{
${ }^{10}$ Following Rogoff (1992) and Bergin and Sheffrin (2000) we will use the real exchange rate as a proxy for Pt. This is how we obtain implications from the model in terms of the exchange rate.

${ }^{11}$ At this point, they use the techniques in Campbell and Mankiw (1989) and Huang and Lin (1993).
} 
Taking expectations in (5) and combining it with (3) one can then get that:

$$
-E_{t} \sum_{i=1}^{\infty} \beta^{i}\left[\Delta n o_{t+i}-\gamma_{t+1}^{*}\right]=C A_{t}^{*}
$$

after defining $C A_{t}^{*} \equiv n o_{t}-c_{t} \cdot{ }^{12}$

Equation (6) is the more relevant equation of the model and it clearly illustrates the consumption smoothing character of the current account. On the one hand, ceteris paribus, the current account falls when net output is expected to raise as the representative consumer smoothes its consumption. On the other hand, ceteris paribus, the current account also falls if the consumption-based real interest rate is expected to decrease. The representative consumer substitutes away future consumption for current consumption that increases over its smoothed level.

\subsection{Testable implications of the model}

Empirical applications of intertemporal current account models in the literature have traditionally extended, to a small open economy, the tests for the permanent income hypothesis model developed by Campbell (1987) and Campbell and Shiller (1987). ${ }^{13}$ We will follow this approach here too. ${ }^{14}$

The model outlined above has several testable implications. First, equation (6) implies that $C A^{*}$ should Granger cause $\Delta n o$ and $r^{*}$ but not the other way around. That is, $C A^{*}$ should have incremental explanatory power for future values of $\Delta n o$ and $r^{*}$. This can be tested empirically.

A second implication of the model that can be tested empirically is provided by equation (3), $E_{t} \Delta c_{t+1}=\gamma E_{t} r_{t+1}^{*}$. It is possible to show analytically that testing equation (3) is equivalent to testing $E\left(R_{t} \mid \mathrm{I}_{t-1}\right)=0$ where $R_{t} \equiv C A_{t}^{*}-\Delta n o_{t}-\gamma r_{t}^{*}-(1 / \beta) C A_{t-1}^{*}$. That is, the difference between the forecast and the actual current account is unpredictable, given the relevant information set. We will call this test the R-test.

There is a third approach for testing the model if one is willing to make specific assumptions about how individuals form their expectations. This is the approach pursued, for instance, by Sheffrin and Woo (1990). Consider that the behavior of the three variables of interest, $\Delta n o$, $C A^{*}$ and $r^{*}$ can be modelled according to an unrestricted autoregressive process of order 1 , $\operatorname{VAR}(1)$, of the following shape: ${ }^{15}$

\footnotetext{
${ }^{12}$ In the per period budget constraint in (1) intuitively one could define $C A_{t}=B_{t}-B_{t-1}=N O_{t}-C_{t}$. The definition of $C A_{t}^{*}$ in (6) has the same idea but with the variables expressed in log terms. This measure of the current account is approximately the ratio of the trade balance to consumption in the economy.

${ }^{13}$ See, for instance, Sheffrin and Woo (1990), Otto (1992), Ghosh (1995), Iscan (2002), Gruber (2004) and Nason and Rogers (2006).

14 Glick and Rogoff (1995) and Gruber (2002) consider that Investment is endogenous and follow a different empirical approach.

${ }^{15}$ This can be easy generalized for higher order VARs.
} 


$$
z_{t} \equiv\left[\begin{array}{l}
\Delta n o \\
C A^{*} \\
r^{*}
\end{array}\right]_{t}=\left[\begin{array}{lll}
a_{11} & a_{12} & a_{13} \\
a_{21} & a_{22} & a_{23} \\
a_{31} & a_{32} & a_{33}
\end{array}\right]\left[\begin{array}{l}
\Delta n o \\
C A^{*} \\
r^{*}
\end{array}\right]_{t-1}+\left[\begin{array}{l}
u_{1 t} \\
u_{2 t} \\
u_{3 t}
\end{array}\right]
$$

where $u_{t}$ is a three dimensional vector of mean zero, homoskedastic errors.

Equation (7) implies that $E_{t}\left(z_{t+i}\right) \equiv A^{i} z_{t}$ and provides an empirical estimate of the expected future values of these variables at every horizon. $C A^{*}$ is included in (7) because according to the model, as mentioned above, $C A^{*}$ should have incremental explanatory power for future values of $\Delta n o$ and $r^{*}$.

Equation (6) can be expressed in this context as:

$$
h z_{t}=-\sum_{i=1}^{\infty} \beta^{i}\left(g_{1}-\gamma g_{2}\right) A^{i} z_{t}
$$

where $g_{1}=\left[\begin{array}{lll}1 & 0 & 0\end{array}\right], g_{2}=\left[\begin{array}{lll}0 & 0 & 1\end{array}\right]$ and $h=\left[\begin{array}{lll}0 & 1 & 0\end{array}\right]$

or as:

$$
C A_{t}^{*}=k z_{t}
$$

where $k=-\left(g_{1}-\gamma g_{2}\right) \beta A(\mathrm{I}-\beta A)^{-1}$

The vector $k$ has to equal $\left[\begin{array}{lll}0 & 1 & 0\end{array}\right]$ implying that $C A_{t}^{*}=C A_{t}^{*}$. This can also be tested empirically. This test, it is important to notice, is a joint test of the model and of the process of generation of expectations in the economy. We will call this test the k-test.

\section{The data}

The model presented in the previous section provides us with a benchmark for understanding fluctuations in a small open economy's current account. According to that benchmark, fluctuations in a country's current account are motivated by a desire to smooth consumption in a context of changing relative prices and changing expectations about future income. The following sections will take this benchmark model to the data. But before that, this section describes the data employed in the empirical analysis and how the relevant variables and parameters are defined.

The data includes all member countries of the EMU except Luxemburg, whose current account, we believe, is mostly affected by different mechanisms than the ones considered in our benchmark model. We are interested in understating the fluctuations in the current account of these countries over the last three decades. We follow the literature and use quarterly data seasonally adjusted at annual frequency. ${ }^{16}$ The use of quarterly data excludes Greece from the analysis since we could not find data of this frequency for this country that were comparable to

\footnotetext{
${ }^{16}$ It has been shown in the literature that the empirical evaluation of intertemporal current account models using annual data produces misleading results.
} 
that of the other countries. Unless otherwise noted, all the data comes from the International Financial Statistics (IFS) constructed by the International Monetary Fund.

The variables needed for the analysis are defined as follows. Current account $\left(C A_{t}^{*}\right)$ is defined as the difference between net output $\left(n o_{t}\right)$ and consumption $\left(c_{t}\right)$. Net output is the log of GDP $\left(Y_{t}\right)$ minus government expenditure $\left(G_{t}\right)$ and investment expenditure $\left(I_{t}\right)$. Consumption is the log of private consumption expenditure $\left(C_{t}\right)$. All these variables are expressed in per capita terms in order to accommodate the data to the representative consumer assumption of the model. ${ }^{17}$

We use the ex-ante world real interest rate as a measure of the world real interest rate $\left(r_{t}\right)$ in the model. This is computed as the difference between the one year world nominal interest rate and expected inflation, where expected inflation is calculated from a forecast based on a 6 quarter window. Bergin and Sheffrin (2000) define the world short-term nominal interest rate combining short-term nominal interest rates, T-bill rates or equivalent measures for the G-7 countries. They then apply this common world interest rate to all their countries. Here we follow a different approach. In particular, we define the world short-term nominal interest rate for each country as the Short-Term Interest Rate provided by the OECD Economic Outlook. ${ }^{18}$ Except for the period after the introduction of the Euro, this world nominal interest rate differs across countries. We believe, however, that this provides a better representation of the world interest rates faced by each country than the one used in Bergin and Sheffrin (2000).

As mentioned in section 3, we follow Rogoff (1992) and Bergin and Sheffrin (2000) and we use the ex-ante real exchange rate as a proxy for $P_{t}$. In particular, we use the real effective exchange rate constructed by the IFS using relative unit labour costs, and we construct the exante real effective exchange rate again from a forecast based on a 6 quarter window. ${ }^{19}$ Finally, and following the literature, we focus on the dynamic implications of the model and de-mean all the relevant variables relative to their sample mean.

We also need to give values to the three parameters of the model: $a$, the relative share of traded goods in consumption, $\beta$, the discount rate, and $\gamma$, the intertemporal elasticity of substitution. The share of traded goods in consumption is estimated from the input-output information for every country provided by Eurostat. This data refers to 1995 for most countries. Given that 1995 lies in the later part of our sample and that the consumption of no traded goods in developed economies is likely to have increased over time, the ratio of traded goods in consumption is likely to have been higher in the earlier part of the sample. Nevertheless, we believe this to be an appropriate approximation and the results to be robust to this parameter. For the discount rate, we defined it as $\beta=\frac{1}{1+\bar{r}}$, where $\bar{r}$ denotes, for each country, the average of the quarterly real interest rate during the period.

There exists a wide range of estimates for the intertemporal elasticity of substitution in the literature depending on the context and manner in which it is estimated. In this sense, while

\footnotetext{
${ }^{17}$ Population data comes from the OECD Economic Outlook.

${ }^{18}$ The OECD Economic Outlook does not provide this information for Austria. Thus, for the empirical analysis, we constructed the world short-term nominal interest rate for Austria combining the information about the Money Market rate provided by the IFS for this country prior to the creation of the Euro with the short-term nominal interest rate in the Euro area after the introduction of the Euro.

${ }^{19}$ For Portugal, we use a real effective exchange rate computed based on relative consumer prices as the IFS does not provide for this country the one based on relative unit labour costs.
} 
Hall (1988) estimates it to be small and unlikely larger than 0.1, others have provided estimates much closer to one (see, for example, Beaudry and van Wincoop (1996)). Given the lack of agreement in the literature about this parameter, we take a neutral approach and provide results for several values of $\gamma$ on the interval $(0,1)$. In particular, we consider 0.1, 0.25, 0.5, 0.75 and $0.9 .^{20}$ We believe these numbers cover all the reasonable range for the value of this elasticity.

Table 1 shows for each country some basic information about the parameter values and the data used in the estimation considering $\gamma=0.25$. The first row reports the sample period used for each country. This is the longest time period for which all the needed information is available and, for most countries, it goes from the late 1970s to 2005. There are two exceptions, Germany and Ireland. For Germany data only starts in 1991 after the re-unification and for Ireland quarterly data is only available starting in 1997. This certainly affects the ability of the model to explain the current account fluctuations in these countries. The model described above implicitly considers that $\Delta n o, C A^{*}$ and $r^{*}$ are stationary variables. In fact, it would be difficult to justify that these variables were not stationary over a long period of time. In a short period of time, however, some of these variables could be non-stationary. Then, intuitively, given that one of the implicit assumptions of the model is not satisfied, it should not be surprising to find a poor empirical fit of the model when evaluated in such a short period of time. As it will be clear below, this is what it will happen, to some extent, for Germany and Ireland.

The share of traded goods ranges from 0.26 in Netherlands and Finland to 0.42 in Portugal. There is a negative correlation between this share and per capita income. ${ }^{21}$ The richer European countries tend to have a lower share than the relatively poorer countries. The discount factor does not show many differences across countries, although it is slightly lower for Belgium, Finland and Italy. Belgium and Italy were the two countries with the largest ratio of debt to GDP during the period maybe indicating the existence of a risk premium in their discount factor. Large differences exist in the mean values of our measure of the current account among countries. Portugal has by far the smallest mean value at -0.16 . In contrast, Ireland shows the largest surplus, 0.27, although the sample period for Ireland is substantially shorter. In understanding these numbers, it is important to recall that our measure of the current account is approximately equal to a country's external balance over consumption. Netherlands also shows a large mean surplus of 7.66\% over a 29 year period. All the other countries have positive mean current account balances except Spain, although their absolute values are substantially smaller.

\section{Testing the ICA model}

Table 2 presents the results of the R-test, the k-test and the Granger causality tests. These tests use the longest time period available for each country and they are performed for each of the five values of $\gamma$ described in the previous section.

\footnotetext{
${ }^{20}$ Bergin and Sheffrin (2000) also consider different values of $\gamma$ in their empirical analysis. In addition, they present the results of their model for an 'estimated' $\gamma$, defined as the value of $\gamma$ that maximizes the p-value of the k-test of the model. We found this estimated $\gamma$ to be extremely non-robust to minor changes in the specification of the model and that is why we did not pursue that approach here.

${ }^{21}$ This correlation is about -0.35 .
} 
Recall that the R-test consists on testing if $E\left(\left.R_{t}\right|_{t-1}\right)=0$. To implement this test we simple regress $R_{t}$ on lags of $\Delta n o_{t}, \mathrm{i} C A_{t}^{*}$ and $\mathrm{i} r_{t}^{*}$, that is on $I_{t-1}$, and test the null hypothesis that the estimated coefficients associated to the independent variables are all zero. The k-test of the model, as described in section 3.1, tests the null hypothesis that the vector $k$ is equal to $\left[\begin{array}{lll}0 & 1 & 0\end{array}\right]^{22}$ Bergin and Sheffrin (2000) show that this test can be implemented using the delta method to construct a $\chi^{2}$ statistic for that hypothesis. The values reported on Table 2 for these two tests correspond to the p-values associated to the null hypothesis.

Finally, recall that variable $X$ Granger causes variable $Y$ if it provides any statistically significant information about $Y$ in the presence of lagged $Y$. Thus, a natural way of implementing this test is to regress $Y_{t}$ on lags of $Y_{t}$ and $X_{t}$, and then test the null hypothesis that the estimated coefficients associated to the lags of $X_{t}$ are all zero. Table 2 reports two values for the Granger causality tests. The first value corresponds to the $\mathrm{p}$-value associated to testing the hypothesis that $C A_{t}^{*}$ does not Granger cause $\left[\Delta n o_{t}-\gamma_{t}^{*}\right]$. The second value of the Granger causality test provided in the table is the p-value associated to testing the hypothesis that $\left[\Delta n o_{t}-r_{t}^{*}\right]$ does not Granger cause $C A_{t}^{*}$. In this case, a rejection of the model at a $10 \%$ significance level requires that the first $\mathrm{p}$-value be greater than 0.1 and the second $\mathrm{p}$-value be smaller than 0.1 .

Table 2 also provides information about the number of lags considered for each country and each value of $\gamma$, which is relevant for the construction of all the three tests mentioned above. This number of lags is determined applying the Akaike's, the Schwarz's Bayesian, and the Hannan and Quinn Information Criteria to the vector auto regression composed of variables $\Delta n o_{t}, C A_{t}^{*}$ and $r_{t}^{*}$. When these three criteria indicate different number of lags, we use the mode of the recommendation. For the case in which all three suggest alternative number of lags, the Akaike's Information Criteria (AIC) always suggests the largest number. Then, given that the AIC is known to be biased toward selecting more lags than needed, in those cases we choose the middle estimate of the three criteria.

The evidence from the R-test indicates that the intertemporal model is rejected for all different values of $\gamma$ for Austria, Finland, Germany and Ireland. For the other six countries (Belgium, France, Italy, Netherlands, Portugal and Spain), the model is always rejected for values of $\gamma$ equal or above 0.75 , but is never rejected for values of the intertemporal elasticity of substitution below $0.75 .^{23}$

The k-test corroborates most of the conclusions of the R-test. Namely, (i) the model is always rejected for Austria, Finland, Germany and Ireland, and (ii) the model can not be rejected for Belgium, France, Italy and Netherlands as long as $\gamma<0.75$. There are, however, some discrepancies between the two tests. In particular, according to the k-test: (i) the model is always rejected for Portugal, (ii) the model can not be rejected for Spain only when $\gamma=0.5$, and (iii) in some instances the model can not be rejected either for Belgium, France, Italy and Netherlands when $\gamma \geq 0.75$. Mercereau and Miniane (2004), show that the k-test may produce

\footnotetext{
${ }^{22}$ The vector $\mathrm{k}$ is a three-dimensional vector only for a VAR(1). For countries for which a VAR(2) is used $k$ is a vector with six elements. The null hypothesis in that case is that $\mathrm{k}$ is equal to $\left[\begin{array}{llllll}0 & 0 & 1 & 0 & 0 & 0\end{array}\right]$.

${ }^{23}$ We place the level of rejection at the $10 \%$ significance level.
} 
misleading results if one of the series in the VAR is highly persistent. ${ }^{24}$ This is typically the case for the current account in the countries in our sample. Therefore, we place more emphasis on the predictions of the R-test in interpreting these small discrepancies between the two tests.

Finally, the Granger causality tests produce mixed results that are difficult to conciliate with the results of the previous two tests. This is also the case in most of the empirical applications of intertemporal current account models in the literature. This is not surprising since these tests are really 'weak' tests of the model. For this reason, we follow the literature and do not place too much emphasis on the results of these tests.

In order to assess the robustness of the results presented in Table 2 we evaluate their sensitivity to different time periods. Table 3 presents the same information as Table 2 for five different time periods (1980q1-2005, 1985q1-2005, 1990q1-2005, 1980q1-1998q4 and 1977q1-1998q4). ${ }^{25}$ The results are broadly consistent with the ones presented in Table 2. Namely, (i) the model is always rejected for Austria and Finland, and (ii) in most of the cases it is not possible to reject the model for Belgium, France, Italy, Netherlands, Portugal and Spain for small values of $\gamma$.

Summing up, we view this empirical exercise as providing broadly support to two main conclusions. First, that the model is rejected for Austria, Finland, Germany and Ireland regardless of the value of $\gamma$. As mentioned above, rejection for Germany and Ireland is not surprising given their small sample periods. Finland is also a somewhat special case given its special economic relationship with the former Soviet Union, especially in the early part of the sample. Rejection for Austria is harder to explain. And second, that for the other six countries (Belgium, France, Italy, Netherlands, Portugal and Spain) rejecting the model is more difficult especially for values of the intertemporal elasticity of substitution smaller than 0.75 .

\section{Implications from the ICA model: current account dynamics}

The results presented in the previous section indicate that it is not possible to reject our benchmark model for Belgium, France, Italy, Netherlands, Portugal and Spain as long as the intertemporal elasticity of substitution is not too big. Fluctuations of the current account balances in these countries over the last three decades can be understood as the reaction of these countries to changing expectations about future income and relative prices in their attempt to smooth their consumption over time. Given the performance of the model for these six countries and for small values of $\gamma$, we explore in this section more of its implications. In doing that, we focus, in the case in which $\gamma=0.25$. We choose to show the additional implications of the model for this value of $\gamma$ for expositional convenience and because it is broadly in the middle of the range of values of $\gamma$ for which the model performs well. Most of the results presented below also hold when $\gamma=0.1$ or $\gamma=0.5$.

Table 4 reports, for each country, the estimates of the parameters composing the VAR companion matrix in equation (7) with their corresponding standard errors. As the theory suggests, ceteris paribus, a current account surplus predicts smaller changes in net output in the

\footnotetext{
${ }^{24}$ With high persistence in one of the VAR series, the delta method approximation needed to test the null hypothesis of the k-test is less accurate.

${ }^{25}$ Germany and Ireland are not included in this exercise given their small sample sizes.
} 
future. The estimate of $\Delta n o: L C A^{*}$ is negative for all countries with the exception of France. ${ }^{26}$ Consistent with the theory, we also find that, ceteris paribus, a current account surplus implies higher consumption-based real interest rates in the future. The estimate of $r^{*}: L C A^{*}$ is positive for all countries. Most of these coefficients, although with the expected sign, are statistically insignificant, as expected given the mixed performance from the Granger causality analysis discussed above.

Table 5 reports, for each country, the estimates of the parameters composing the $k$ vector, with their corresponding standard errors. As shown in Table 2, it is not possible to reject that the $k$ vectors for Belgium, France, Italy and Netherlands are equal to the predictions of the model. It is true, however, that the estimated parameters have very large standard errors and that, in some cases, the point estimates are far from their expected values. For instance, the point estimate of the coefficient on $C A_{t}^{*}$ for Netherlands, although not statistically different from 1, is below 0.5 . In contrast, Portugal has a point estimate of the $k$ vector far from the model's prediction and rejects the null hypothesis of the k-test. Spain, set on the margin of rejecting the null hypothesis of the k-test according to Table 2, has point estimates of the components of the $k$ vector closer to the model's prediction.

Figure 3 shows, for each country, the evolution over the sample period of the predicted current account, computed according to the estimated $k$ vector, and of the actual current account. From the figure, it is clear that the model makes a relatively good job in capturing, qualitatively, the fluctuations in each country's current account. Quantitatively, however, the model performs better for France and Italy (the fit is almost perfect) than for the other countries.

The top panel in Table 6 complements the impressions obtained from the visual analysis in Figure 3. The first row of Table 6 reports, for each country, the ratio of the standard deviation of the actual and the predicted current accounts. This ratio is almost equal to 1 for France and Italy, it is clearly above 1 for Belgium and it is substantially below 1 for Netherlands, Portugal and Spain. The fact that the predicted current account for the last three countries exhibits less volatility than the actual one should not be surprising since this is a common feature of the empirical applications of intertemporal current account models in the literature (see Obstfeld and Rogoff, 1995). ${ }^{27}$ Instead, it is somehow surprising, given this evidence, the excess volatility we find in the predicted current account for Belgium.

An alternative summary statistic of the relative performance of the model is the average over the sample period of the ratio of the predicted value of the current account and its actual value. This ratio is reported in the fourth row of Table 6. This ratio is almost one for France and Italy, larger than one for Belgium, and smaller than one for Netherlands, Portugal and Spain. For these latter countries, the model not only under-predicts the volatility of the current account buy also its level.

Current account fluctuations in the model are due to changes in expectations about future net output or about future relative prices. We can use equation (6) to decompose the predicted

\footnotetext{
${ }^{26}$ For France, we do find, however, that the coefficient of the effect that second lag of the current account has on output is also negative.

27 There have been a number of suggestions in the literature to increase the volatility of the current account predicted by ICA models. For instance, Gruber (2004), shows that including habits in the consumers' utility function helps a lot in matching the observed volatility.
}

14 - IESE Business School-University of Navarra 
current account into these two components. In particular, we can express the predicted current account as:

$$
\overline{C A_{t}^{*}}=-E_{t} \sum_{i=1}^{\infty} \beta^{i}\left(\overline{\Delta n o_{t+i}}\right)+E_{t} \sum_{i=1}^{\infty} \beta^{i}\left(\overline{\gamma r_{t+i}^{*}}\right)
$$

where $\bar{x}$ denotes the estimated value from the VAR of variable $x$.

The second and third rows in Table 6 report the average percentage contribution to the predicted current account of these two components over the sample period. ${ }^{28}$ Figure 4 also shows, for each country, the relative contribution to the predicted current account of these two terms throughout the sample period. There are important differences across countries. Expectations of future relative prices are the key component of the current account fluctuations predicted by the model for France, Italy and Netherlands. For the last two countries they represent above 70\% of these fluctuations. Instead, for Belgium, Portugal and Spain, the key component are the expectations of future output changes, especially for Portugal where they represent more than $80 \%$ of the predicted fluctuations.

The results above show that current accounts over the last few decades in Belgium, France, Italy, Netherlands, Portugal and Spain are broadly consistent with their citizens smoothing consumption according to their expectations about future income and about future relative prices. Thus, according to our benchmark model, the size and sustainability of current account imbalances in these countries depend on the 'feasibility' of the expectations about future output and relative prices which are driving them. The emphasis on feasibility is key. If these expectations turn out to be far from what seems like a reasonably feasible outcome present current accounts may signal future potential problems. This is, for instance, the concern posed by Gourinchas (2002) when analyzing the evolution of current account deficits in some Euro area countries. If these countries' expectations are over-optimistic or, simply, unrealistic, large current account deficits based on consumption smoothing may lead to sharp adjustments on the current account once these expectations are not realized. ${ }^{29}$

We can use the decomposition of the determinants of the current account highlighted above to extract more information about the countries' expectations about future net output and relative prices. We will focus on the expectations about future net output. To begin with, note that one can manipulate equation (8) and rewrite the current account predicted by our benchmark model as:

$$
\overline{C A_{t}^{*}}=\left(n o_{t}-n o_{t}^{*}\right)+\gamma E_{t} \sum_{i=1}^{\infty} \beta^{i} \overline{r_{t+i}^{*}}
$$

where $n o_{t}^{*}$ is defined in such a way that:

$$
E_{t} \sum_{i=0}^{\infty} \beta^{i} \overline{n o_{t+i}}=\sum_{i=0}^{\infty} \beta^{i} n o_{t}^{*}=\frac{1}{1-\beta} n o_{t}^{*}
$$

\footnotetext{
${ }^{28}$ In order to focus on the sources of variation for balances away from zero, we have only computed the breakdown for the subset of observations for which $\left|\overline{C A_{t}^{*}}\right|>0.01$.

${ }^{29}$ The literature has named these sharp adjustments 'current account reversals'.
} 
In words, equation (10) simply states that $n o_{t}^{*}$ is the level of net output such that an infinite flow of net output fixed at that level has the same presented discounted value as the flow of net output expected by the country's representative consumer, $\left\{\overline{n o_{t+i}}\right\}_{i=0,1,2, \ldots}$. Thus, in a sense, $n o_{t}^{*}$ has a similar interpretation to the permanent income in consumption models and we will refer to it as the country's structural net output. With this concept in mind, the consumption smoothing interpretation of equation (9) is very clear: abstracting from the role of the consumption-based real interest rate, a country must experience a current account deficit when his structural net output is greater than his current net output and, therefore, it is expecting to grow.

The idea of the structural net output allows evaluating, to some extent, the 'feasibility' of a country's expectations about its future net output which, according to our benchmark model, are the driving force behind its current account balances. To begin with, Figure 5 shows the evolution over time of the ratio of each country's structural net output $\left(n o_{t}^{*}\right)$ to its current net output $\left(n o_{t}\right)$. There are some interesting patterns in these figures.

The creation of the Euro increased future output expectations in the Southern European countries. For France, Italy, Portugal and Spain the ratio of the structural net output to the current net output began to increase at some moment in the second half of the previous decade and continued increasing until approximately $2001 .^{30}$ Since then the pattern has differed across these countries. While all countries experienced a downward adjustment in this ratio around that period, for France and Spain it quickly started again an upward trend that continues today. For Italy, however, the ratio stabilized and for Portugal it has continued to decrease reflecting more conservative Portuguese expectations about its future growth. The experiences of Belgium and Netherlands are completely different. For these countries, the ratio of the structural net output to the current net output, although fluctuating, has exhibited no trend around or since the creation of the Euro.

An alternative way of evaluating the 'feasibility' of each country's expectations about its future net output is to compute, for each country, some 'implied' growth rates from this future net output and to compare them with historical growth rates. This can be approximated by the following exercise. Focusing on the last observation for each of our six countries $(t=T)$, net output equals $n o_{T}$ and each country's representative consumer expectations about future net output are given by $\left\{\overline{n o_{T+i}}\right\}_{i=0,1,2, \ldots}$, with an associated structural net output equal to $n o_{T}^{*}$. By definition of the structural net output we know that:

$$
E_{t} \sum_{i=0}^{\infty} \beta^{i} \overline{n o_{T+i}}=\sum_{i=0}^{\infty} \beta^{i} n o_{T}^{*}
$$

Now note that the future net output flow expected by the country's representative consumer, $\left\{\overline{n o_{T+i}}\right\}_{i=0,1,2, \ldots}$, may be very erratic. Instead, let us consider a smoother one with the same present discounted value. In particular, consider that the country's net output grows, starting at $n o_{T}$, at constant rate $g(P)$ during $P$ periods (quarters) and then stays at the reached level, $n o_{P}$, forever. This smoother flow has the same present discounted value as $\left\{\overline{n o_{T+i}}\right\}_{i=0,1,2, \ldots}$ as long as $g(P)$ satisfies the following equation:

\footnotetext{
${ }^{30}$ For Portugal this ratio declined briefly around 1999, but this decline was quickly reverted.
} 


$$
E_{t} \sum_{i=0}^{\infty} \beta^{i} \overline{n o_{T+i}}=\sum_{i=0}^{P} \beta^{i}\left(n o_{T}+i g(P)\right)+\sum_{i=T+1}^{\infty} \beta^{i} n o_{P}
$$

where $n o_{P}=n o_{T}+\operatorname{Pg}(P)$

Obviously, $g(P)$ is a decreasing function of $P$. The longer a country has to reach its constant level of output, the smaller the growth rate in the interim period will have to be.

Table 7 reports the resulting $g(P)$ for several values of $P$. In particular for $P$ equal to $12,20,40$ and 80 quarters, which correspond to transition periods of 3, 5, 10 and 20 years, respectively. The first panel of Table 7 reports the values of $g(P)$ computed according to equation (12) and expressed in annual terms. When analyzing these numbers it is important to note that, in our analysis, all the relevant variables have been demeaned, and net output $(n o)$ is a zero-mean variable. The $g(P)$ numbers should be interpreted as incremental growth rates beyond each country's growth rate over the sample. For that reason, the second panel of Table 7 reports the same annual growth rates of the first panel but expressed relative to each country's sample means.

Countries whose current net outputs $\left(n o_{T}\right)$ are above their structural net outputs $\left(n o_{T}\right)$ have expectations of future growth that are below their historical levels. This is the case for of Belgium, Netherlands and Portugal. On the opposite side, France, Italy and Spain, have current net outputs in the last period $\left(n o_{T}\right)$ below their structural net outputs $\left(n o_{T}^{*}\right)$. Thus, they have expectations of future growth that are above their historical levels.

Belgium and Spain are the two most salient countries. They are, by far, the countries with the most pessimistic and optimistic expectations, respectively, about future net output growth. According to our estimates, on a 5 years time period, Belgium's expectations would imply a growth 24\% slower than its historical mean. Spanish expectations, instead, are at an historical high (as illustrated in Figure 5) and would imply a growth over the same period of time 44\% faster than its historical mean. If we assume that the shares of government expenditure and investment to GDP remain constant, this is equivalent to an increase in GDP per capita during this period of similar magnitude. ${ }^{31}$ Moreover, it is somehow worrisome that, despite considering these high expectations of output growth in Spain, the model can only explain 64\% of the Spanish actual current account deficit at the end of 2005 (third row in the last panel of Table 6).

\section{Robustness checks and further discussion}

The empirical analysis developed above imposed, for each country and for the whole period of analysis, stability of the VAR parameters that determine the way in which consumers form expectations about future net output and relative prices. One could argue against this assumption of stability that the creation of the EMU and the introduction of the Euro have modified the way consumers use past information to form these expectations. In this sense, the drastic implications that the Euro has had on member countries in terms of real interest rates and volatility of exchange rates, strongly suggest the possibility of a structural break in the formation of expectations too. Structural break in this context implies that the VAR parameters

\footnotetext{
${ }^{31}$ In Spain, however, the share of investment to GDP in 2005 was substantially higher than the historical average. Thus, part of this adjustment could take place by a reversal of the share of investment in GDP to its historical average.
} 
in equation (7) may have changed after the creation of the EMU. This section analyses, to some extent, this possibility.

A word of caution first. Even if the introduction of the Euro has constituted a structural break in the process of generating expectations, it is important to understand that this break may have occurred in different ways. The structural break may have affected the order of the VAR process driving expectations. Even if the order of the VAR process remains the same and a structural break has happened, the timing of the break may not be easy to determine. A change of the VAR parameters did not have to occur exactly on the date in which the Euro was introduced, i.e. beginning of 1999. It could well have been the case that individuals, anticipating the introduction of the Euro and its effects, have changed the way they formed their expectations well before that date. Despite these cautions, and lacking of a more convincing alternative, the analysis below explores the possibility of a structural break exactly on the date when the Euro was introduced.

There are a number of tests in the literature to evaluate the presence of a structural break in a given process. ${ }^{32}$ The basic idea behind most of these tests though is the same. If the date of the break is known, these tests estimate the process separately before and after the break, and then compare statistically the two sets of parameter estimates. When the date of the test is unknown or there is more than one break point, the tests are more elaborated but they mostly keep the same basic idea. For obvious statistically reasons, however, these tests do not perform well when the break points are close to the beginning or to the end of the sample period. Intuitively, the estimation of the process on the smallest subsample is not reliable if that subsample is too small. For this reason we can not apply the most common tests of structural break to our problem. We believe that the structural break, if any, should have manifested almost at the end of our sample. Then, with very little observations in the post-break sample, our estimation of the VAR in that subsample is not reliable. In fact, in most cases, our variables are not stationary in such a short period of time, as assumed by our benchmark model.

One alternative that could possibly overcome this problem would be to perform panel estimation of the VAR for our six countries on the post-break sample. The increased information available by jointly estimating the VAR on the post-break sample for the six countries may improve the estimation. This approach has, however, important limitations. To begin with, our panel is small both in terms of time periods and of number of countries. Besides the small sample problems, it is also disputable that the six countries in our panel share exactly the same VAR structure even up to (additive) individual fixed effects. Not surprising, the application of this approach lead us to no sensible parameter estimates. ${ }^{33}$

A different approach is proposed by Pesaran and Timmermann (2006) in the context of forecasting with the presence of structural breaks. They show that in a model with one or more breaks it can be optimal to use pre-break data to estimate the parameters of the model used to compute out-of-sample forecasts. Using pre-break data in the estimation may introduce a bias in the forecast but the variance of the forecast error may be reduced (increase efficiency). Pesaran and Timmermann (2006) take this trade-off into account and provide a procedure to determine the optimal amount of pre-break information to use in the estimation of a model that will be used to make forecasts. We followed this procedure under the assumption that a break took place in 1999:q1, with the creation of the Euro. According to this procedure, we found

\footnotetext{
${ }^{32}$ For instance, the Chow test, the CUSUM test, the Nyblom's L Test or the Andrews-Ploberger test.

${ }^{33}$ We followed Holtz-Eakin, Newey and Rosen (1988) to perform the panel estimation of the VAR.
} 
that only post-break information should be used in estimating the model for Belgium, France, Italy and Portugal. For Spain, the procedure recommended to add the information of only the 7 quarters prior to the break. Instead, for Netherlands, using the whole sample was the best strategy. The fact that, in most cases, no pre-break information was needed is not surprising. The estimation of the model in the post-break sample, as mentioned above, was not reliable and it was usually very different from the pre-break estimation. This implied a large bias when considering pre-break information.

Given the limitations for our purposes of these alternative methodologies, we pursue a more informal empirical approach to evaluate the possibility of a structural change in the process of generating expectations with the introduction of the Euro. In particular, for each country, we compare the current account predicted by the model under two different scenarios. In the first scenario, the model is estimated, for each country, using the longest time period available. Instead, in the second scenario the model is estimated using only the pre-break sample, that is, up to 1998:q4. This is a particular case of rolling estimation and, intuitively, if there has been a structural break around 1999 one would expect that the two model's predictions exhibited some differences. Figure 6 shows, for each country, these two predictions (pca Whole Sample and pca Subsample, respectively) together with the actual evolution of the current account (ca). ${ }^{34}$ For most countries, the predicted current account using the parameter estimates from the two different periods are very similar suggesting that there has not been any structural change around 1999 or that, if a structural change has happened, this has been small. France and Belgium are two exceptions. For these countries, the predicted current account from the subsample is quite different from that obtained from the full sample estimation. The former is also much more volatile than the latter.

The second and third panels in Table 6 provide additional information about the possible existence of a structural break with the introduction of the Euro. ${ }^{35}$ These panels reproduce, respectively, the information of the first panel of the table for the post-break sample (second panel) and the last observation (third panel). The relative contributions of the two components of the predicted current account do not seem to have changed substantially between the first and the second panel for the countries considered. The ratio of the volatilities of the predicted and the actual current account does not change substantially either. Two exceptions to these patterns are Belgium and Netherlands, for whom the ratio is significantly closer to 1 in the post-break sample. The main change occurs on the average ratio of the predicted to the actual current account in this last part of the sample. This ratio gets significantly smaller for Italy, Netherlands, Portugal and Spain while for Belgium it increases considerably. ${ }^{36}$

To summarize, although the creation of the Euro could have caused a structural break in the behavior of the current account, the evidence presented in this section is not strongly

\footnotetext{
${ }^{34}$ Note that, by construction, for each country pca Whole Sample is identical to the model's prediction plotted in Figure 3. Note also that the pre-break sample, as opposed to the post-break sample, is long enough to guarantee the reliability of our VAR estimates and the stationary of the relevant variables. Table 3 reports the results of the tests of the model for the shorter sample.

${ }^{35}$ Recall that the decline in real interest rates experienced in many Euro area countries after the introduction of the Euro does not constitute a structural break in our model since the effects of this variable are explicitly modelled. Instead, as mentioned before, we look for a structural break in the formation of expectations.

${ }^{36}$ In the case of Portugal, the strange behavior of this ratio has to do mainly with the fact that its actual current account is very close to 0 .
} 
supportive of the existence of such a break. Alternatively, if the break did happen, it does not seem very large.

One has to be particularly careful when making inter-country comparisons with the results presented above. The tests have been performed on the dynamic implications of the model for each country, around each country's sample means and assuming that these sample means are representative of the steady state of the economy in each country. ${ }^{37}$ As indicated in Table 1 , however, countries are in considerably different situations in terms of their sample values of the relevant variables, which make it difficult to interpret differences across countries in our results. For instance, countries could have been experiencing over the last few years adjustment towards different steady state levels of net foreign assets at potentially different speeds across them.

Finally, another important caveat refers to the key behavioral assumptions in the model that consumers can perfectly smooth their consumption over time and that this can only be done via the external sector (via current account). There is a large literature in consumption analyzing whether consumers perfectly smooth their consumption or not. The results are mixed and, in many cases, they depend on the type of shock consumers receive. But still, there is a large evidence suggesting the existence of capital market imperfections that damage (some) consumers' ability to smooth their consumption over time. Regarding to the second assumption, the main concern is that the external balance is not the only instrument consumers have to smooth their consumption. Fluctuations in investment and other domestic spending (i.e. government expenditure) may also be correlated with consumption. In our model, however, both investment and government expenditure are considered to be exogenous.

Several papers have showed the importance of introducing these factors in the context of current account modelling. Bussiere, Fratzscher and Muller (2004) showed that considering capital market imperfections is not irrelevant. In particular, they extended the ICA model to allow for a fraction of the population to be financially constrained (Keynesian consumers) and they found that, in the new setup, there was a connection between the government fiscal deficits and the current account (in the line of the idea of the "twin deficits").

Endogenous investment has also been dealt in the context of ICA models (see for instance Glick and Rogoff, 1995). Current accounts are in part driven by expectations about future wealth. To the extent that future wealth depends on future productivity gains arising from current investment, current account deficits may be correlated with investment booms and increases in domestic savings. Kraay and Ventura (2000) provide empirical evidence on the importance of investment and portfolio allocations in the context of explaining OECD countries' current account balances. This type of extension could be especially insightful for countries like Spain and Ireland that have recently experienced large increases in investment with very different behavior in their current accounts.

\section{Conclusions}

Current account balances within Euro area countries have diverged over the last decade. Southern European countries like Greece, Portugal and Spain, have presented almost continuously increasing current account deficits while countries like Germany and Austria have continuously improve their current account balances. This paper has used a stylized

\footnotetext{
${ }^{37}$ We only imposed cross-country restrictions to do the panel estimation in the context of the analysis of a structural break.
} 
intertemporal model of the current account to evaluate the behavior of these current account balances over the last three decades.

The intertemporal model is rejected for Austria, Finland, Germany, and Ireland, partly due to lack of sufficient data. However, the model appears to be consistent with the behavior over the last three decades of the current accounts of Belgium, France, Italy, Netherlands, Portugal and Spain. Current account balances in these countries can be explained by the desire to smooth consumption in response to changes in expectations about future output and relative prices. The relative importance of the fluctuations of these components varies by country. Fluctuations in expectations over relative prices explain the majority of current account fluctuations in Italy and Netherlands, while variations in expected output are more important for Belgium, Portugal and Spain.

The creation of the Euro coincided with an increase in expectations of future output relative to existing output for France, Italy, Portugal and Spain, that contributed to current account deficits in these countries. The upward trend in these expectations was slightly reverted around 2001. After that, expectations in Italy have remained essentially constant, while they have decreased in Portugal (coinciding with a phase of low economic activity) and have started an upward trend again in France and Spain. Spain is a special case. According to the model, Spanish expectations about future growth are at historical high levels. Still, the current account predicted by the model underestimates the Spanish current account by almost 40\%. This poses some concerns about the sustainability of the large current account deficits in Spain.

The possibility of a structural change associated with the introduction of the Euro has also been considered. Some informal evidence indicates that a break around 1999 either has not happened or it has not been very large. However, the fact that there are very few post-break observations seriously limited this analysis.

We believe that this paper constitutes a good starting point to understand the current account fluctuations in the Euro area and, in particular, to place them in the context of a very reasonable and standard benchmark. It is true, however, that the model considered here, although broadly consistent with the data, is still very stylized. In this sense, extensions of this model to introduce endogenous investment or capital market imperfections that limit consumption smoothing could certainly improve the quantitative fit of the model and should prove fruitful areas for future research. 


\section{References}

Adalet, M. and B. Eichengreen (2005), “Current Account Reversals: Always a Problem?”, NBER Working Paper No. 11634, September.

Barro, R.J. and X. Sala i Martin (1990), “World Real Interest Rates”, in NBER Macroeconomic Annual (ed. 0.J. Blanchard and S. Fischer), MIT Press, Cambrigde (MA), pp. 15-61.

Beaudry, P. and E. van Wincoop (1996), "The Intertemporal Elasticity of Substitution: An Exploration using a US Panel of Stata Data”, Economica, Vol. 63, No. 251, August, pp. 495-512.

Bergin, P.R. and S.M. Sheffrin (2000), “Interest Rates, Exchange Rates and Present Value Models of the Current Account”, Economic Journal, Vol. 110, pp. 535-558.

Blanchard, 0. (2006), “Adjustment Within the Euro: The Difficult Case of Portugal”, MIT Department of Economics Working Paper No. 06-04.

Blanchard, 0. and F. Giavazzi (2002), "Current Account Deficits in the Euro Area: The End of the Feldstein-Horioka Puzzle?”, Brookings Papers on Economic Activity, Vol. 2, pp. 147-209.

Bussiere, M., M. Fratzscher and G.J. Muller (2004), "Current Account Dynamics in OECD and EU Acceding Countries. An Intertemporal Approach”, ECB Working Paper No. 311, February.

Campbell, J.Y. (1987), "Does Saving Anticipate Declining Labor Income? An Alternative Test of the Permanent Income Hypothesis”, Econometrica, Vol. 55, No. 6, November, pp. 1249-1273.

Campbell, J.Y. and N.G. Mankiw (1990), "Consumption, Income, and Interest Rates: Reinterpreting the Time Series Evidence”, NBER Working Paper No. 2924, May.

Campbell, J.Y. and R.J. Shiller (1987), "Cointegration and Tests of Present Value Models", Journal of Political Economy, Vol. 95, No.5, October, pp. 1062-1088.

Debelle, G. and G. Galati (2005), “Current Account Adjustment and Capital Flows”, BIS Working Papers No. 169.

Dolado, J.J. and J. Viñals (1991), "Macroeconomic Policy, External Targets and Constraints: The Case of Spain”, CEPR Discussion Paper No. 505, January.

Edwards, S. (2005), “The End of Large Current Account Deficits, 1970-2002: Are There Lessons for the United States?”, NBER Working Paper No. 11669, September.

Edwards, S. (2006), "Monetary Unions, External Shocks and Economic Performance: A Latin American Perspective”, NBER Working Paper No. 12229, May.

Freund, C. and F. Warnock (2005), "Current Account Deficits in Industrial Countries: The Bigger They are, the Harder They Fall?”, NBER Working Paper No. 11823, December.

Ghosh, A.R. (1995), "International Capital Mobility Amongst the Major Industrialised Countries: Too Little or Too Much?”, Economic Journal, Vol. 105, No. 428, January, pp. 107-128.

Glick, R. and K. Rogoff (1995), "Global versus Country-Specific Productivity Shocks and the Current Account”, Journal of Monetary Economics, Vol. 35, pp. 159-192. 
Gourinchas, P.O. (2002), "Comments on 'Current Account Deficits in the Euro Area: The End of the Feldstein-Horioka Puzzle?”, by 0. Blanchard and F. Giavazzi', Brookings Papers on Economic Activity, Vol. 2.

Gruber, J.W. (2002), “Productivity Shocks, Habits, and the Current Account”, Board of Governors of the Federal Reserve, International Finance Discussion Paper No. 733.

Gruber, J.W. (2004), “A Present Value Test of Habits and the Current Account”, Journal of Monetary Economics, Vol. 51, pp. 1495-1507.

Hall, R.E. (1988), "Intertemporal Substitution in Consumption”, Journal of Political Economy, Vol. 96, No. 2, April, pp. 339-357.

Holtz-Eakin, D., W. Newey and H.S. Rosen (1988), "Estimating Vector Autoregressions with Panel Data”, Econometrica, Vol. 56, No. 6, November, pp. 1371-1395.

Huang, C. and K. Lin (1993), "Deficits, Government Expenditure, and Tax Smoothing in the United States: 1929-1988”, Journal of Monetary Economics, Vol. 31, No. 3, June, pp. 317-339.

IMF (2002), “World Economic Outlook”, Chapter II, IMF, Washington DC.

Iscan, T.B. (2002), "Present Value Tests of the Current Account with Durables Consumption", Journal of International Money and Finance, Vol. 21, No. 3, June, pp. 385-412.

Kraay, A. and J. Ventura (2000), “Current Accounts in Debtor and Creditor Countries", Quarterly Journal of Economics, Vol. 115, No. 4, November, pp. 1137-1166.

Mercereau, B. (2001), "How to Test (and not to Test) a Present Value Model in the Presence of Persistence”, mimeo.

Mercereau, B. and J. Miniane (2004), "Challenging the Empirical Evidence from Present Value Models of the Current Account”, IMF Working Papers No. 04/106, June, International Monetary Fund.

Nason, J.M. and J.H. Rogers (2006), "The Present-Value Model of the Current Account Has Been Rejected: Round up the Usual Suspects”, Journal of International Economics, Vol. 68, pp.159-187.

Obstfeld, M. and K. Rogoff (1995), "The Intertemporal Approach to the Current Account", Handbook of International Economics (eds. G. Grossman and K. Rogoff), Vol. 3, chapter 34, pp. 1731-1799.

Obstfeld, M. and K. Rogoff (1996), "Foundations of International Macroeconomics”, MIT Press, Cambridge (MA).

Obstfeld, M. and K. Rogoff (2005), “The Unsustainable US Current Account Position Revisited”, CEPR Discussion Paper No. 5416, December.

Otto, G. (1992), “Testing a Present Value Model of the Current Account: Evidence from U.S. and Canadian Time Series", Journal of International Money and Finance, Vol. 11, No. 5, October, pp. 414-430.

Pesaran, M.H. and A. Timmermann (2006), "Selection of Estimation Window in the Presence of Breaks", Journal of Econometrics, forthcoming. 
Rogoff, K. (1992), "Traded Goods Consumption Smoothing and the Random Walk Behavior of the Real Exchange Rate", Bank of Japan Monetary and Economic Studies, Vol. 10, No. 2, November, pp. 1-29.

Sachs, J. (1981), "The Current Account and Macroeconomic Adjustment in the 1970s", Brookings Papers on Economic Activity, No. 1, pp. 201-282.

Sheffrin, S. and W.T. Woo (1990), "Present Value Tests of an Intertemporal Model of the Current Account”, Journal of International Economics, Vol. 29, No. 3-4, November, pp. 237-253. 


\section{Figure 1}

Current account balances and GDP per capita in the Euro area

EMU

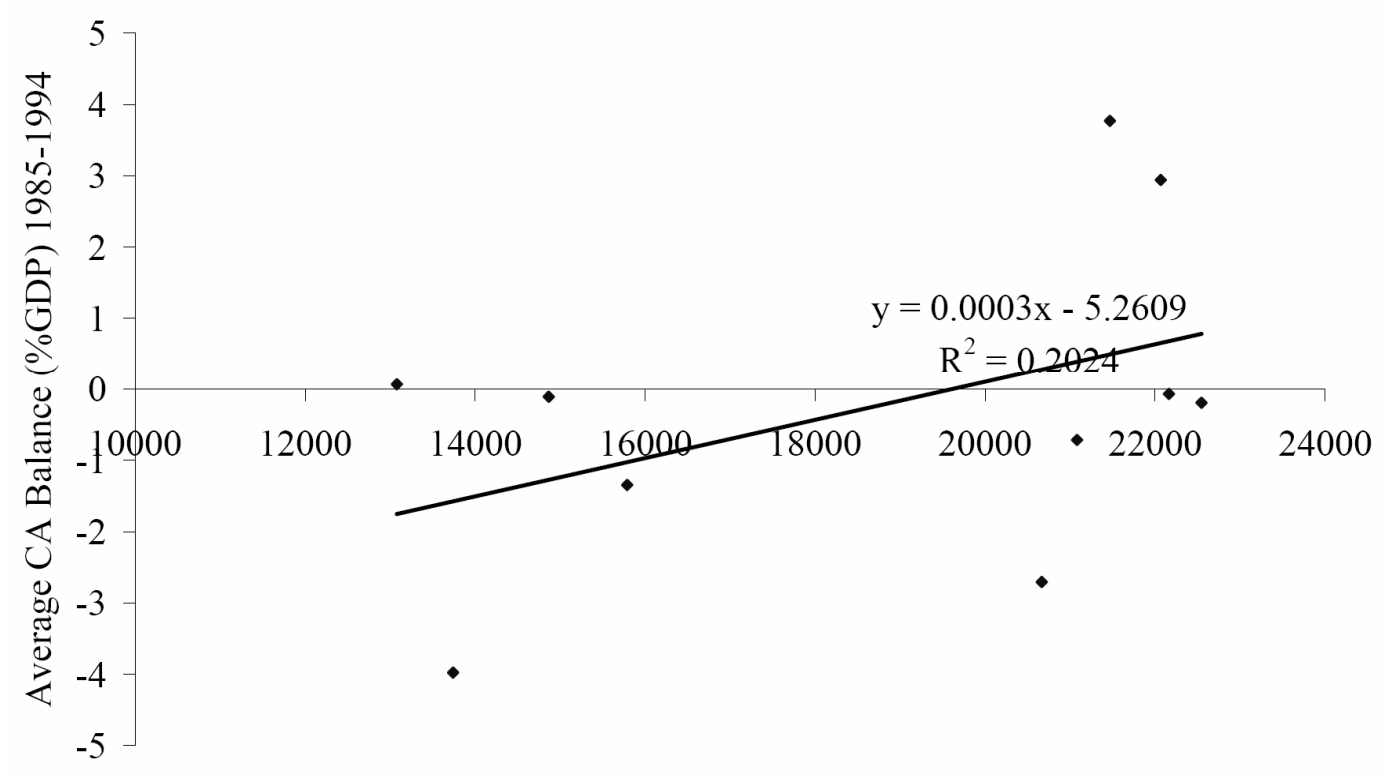

Average GDP per capita constant 2000 PPP, 1985-1994

\section{EMU}

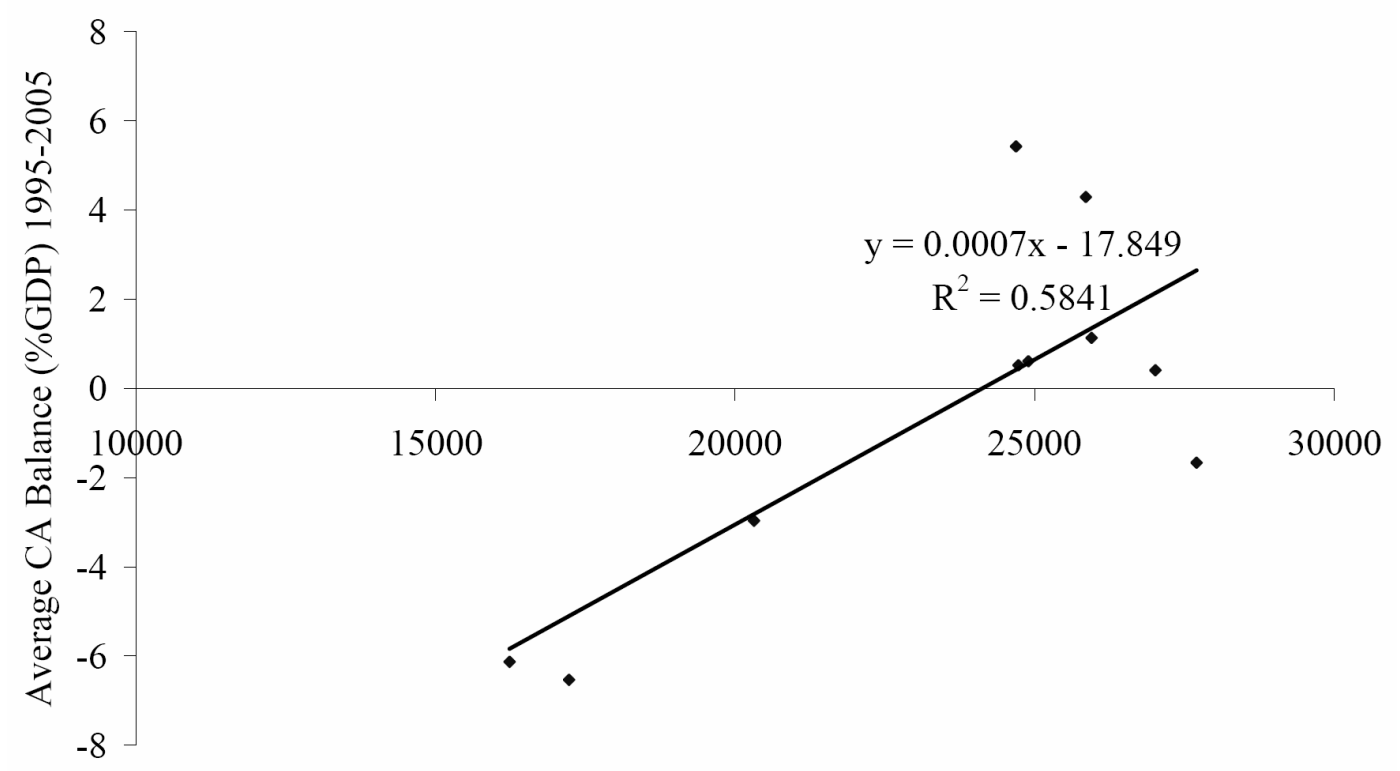

Average GDP per capita constant 2000 PPP, 1995-2004

Source: Own calculations from the OECD Economic Outlook. 


\section{Figure 2}

Standard deviation of current account balances 1975-2005

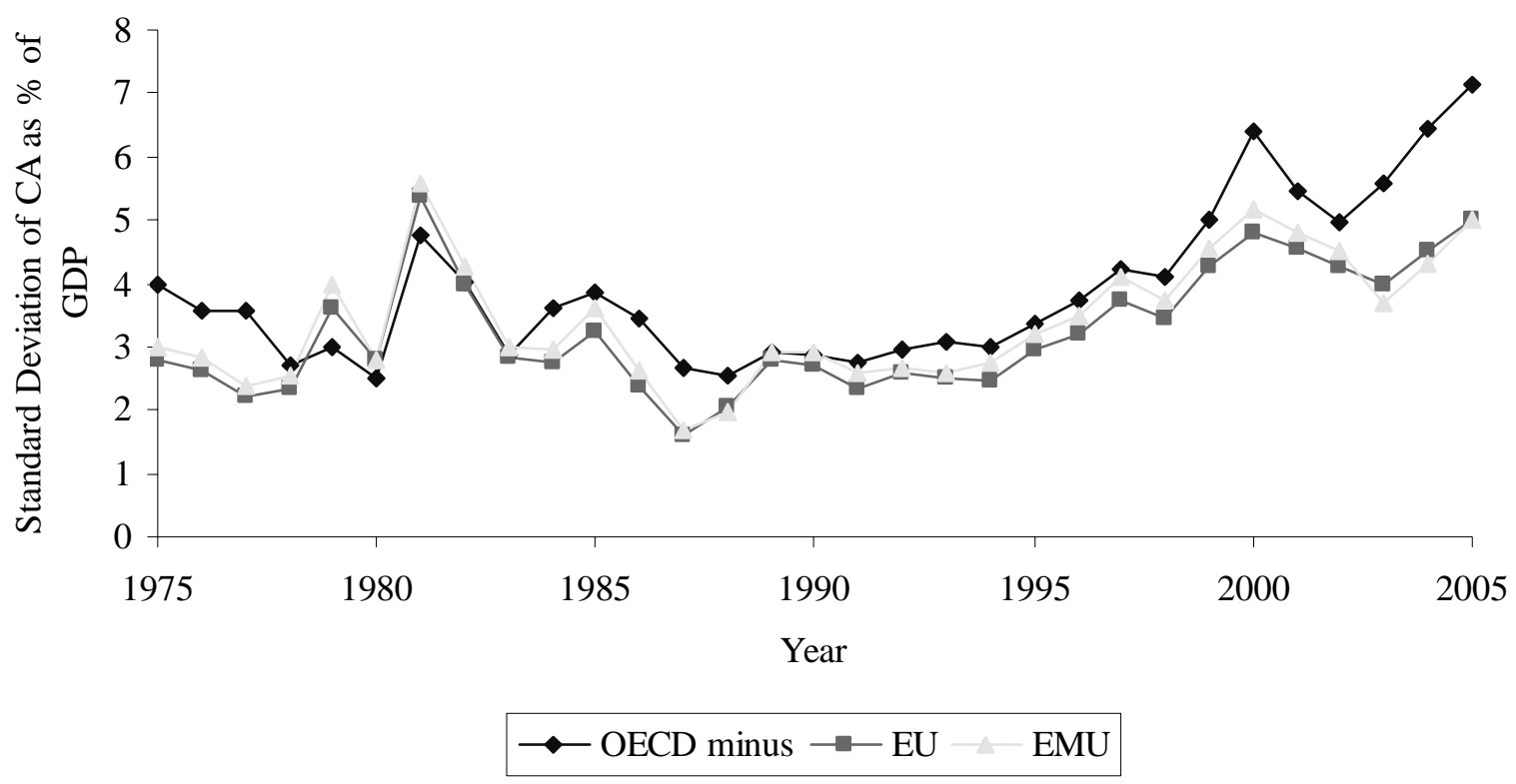

Source: Own calculations from the OECD Economic Outlook. 
Figure 3

Actual and predicted current account
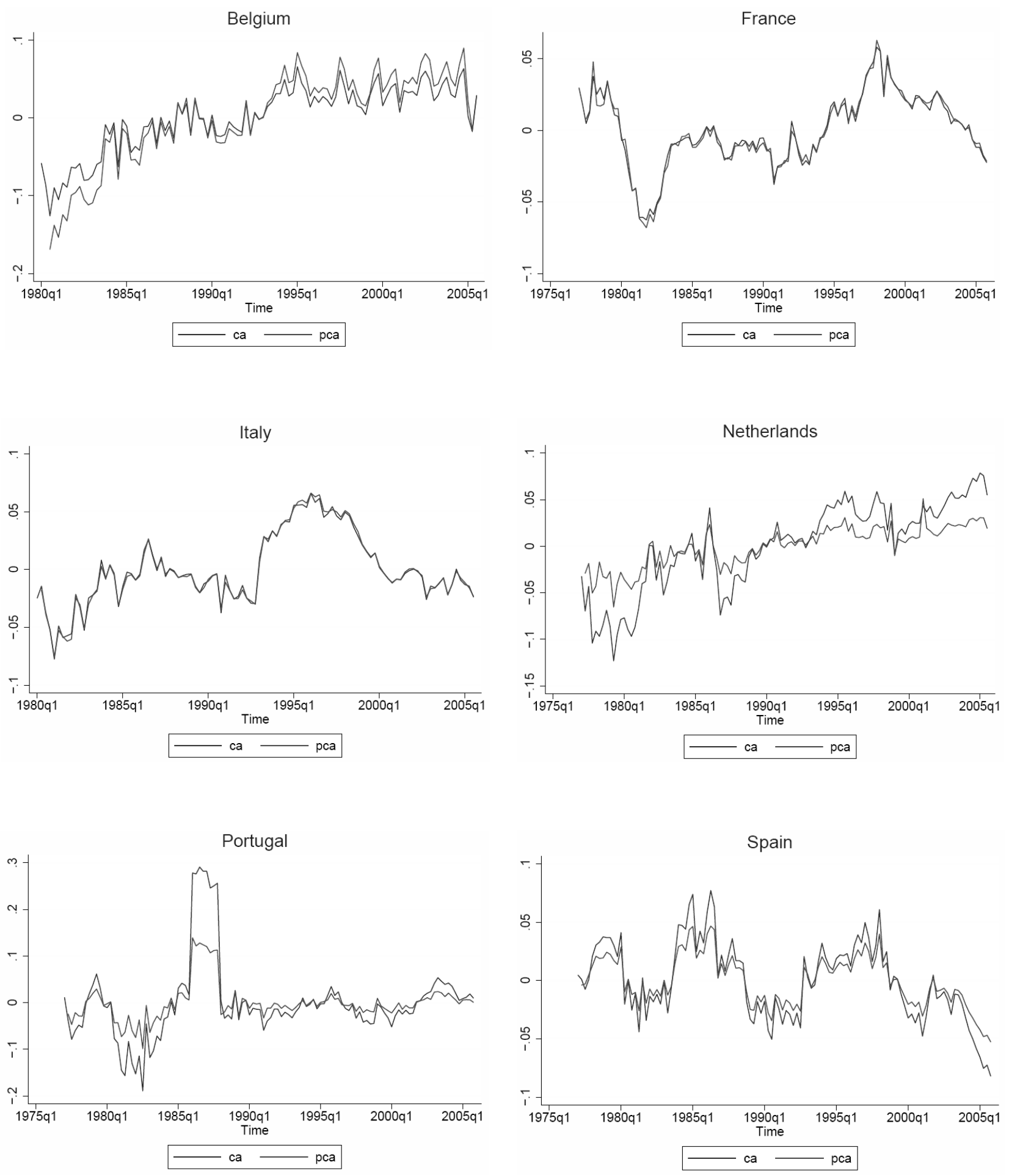


\section{Figure 4}

Predicted current account decomposition: Net output and relative price components
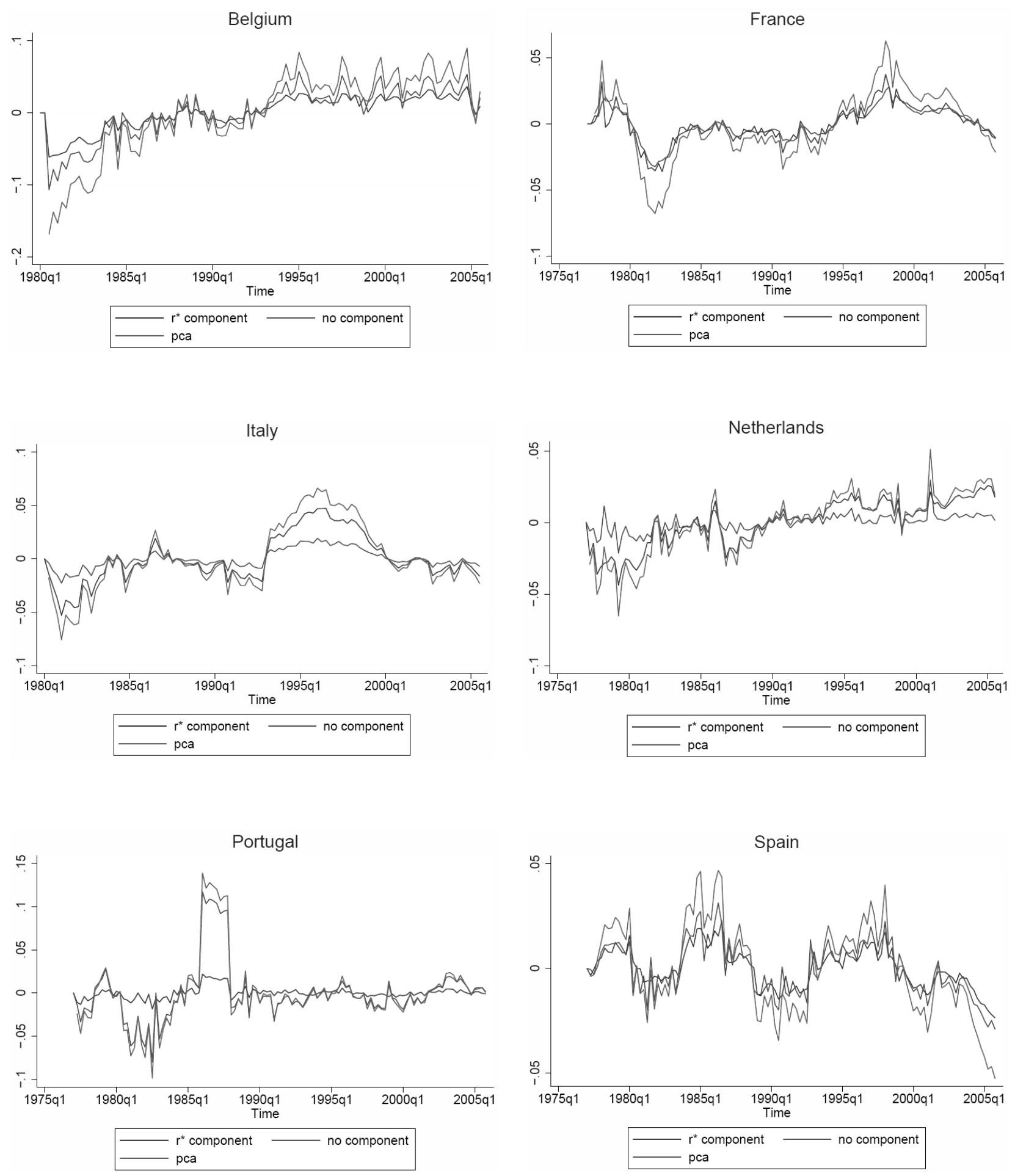


\section{Figure 5}

Ratio of structural net output to current net output
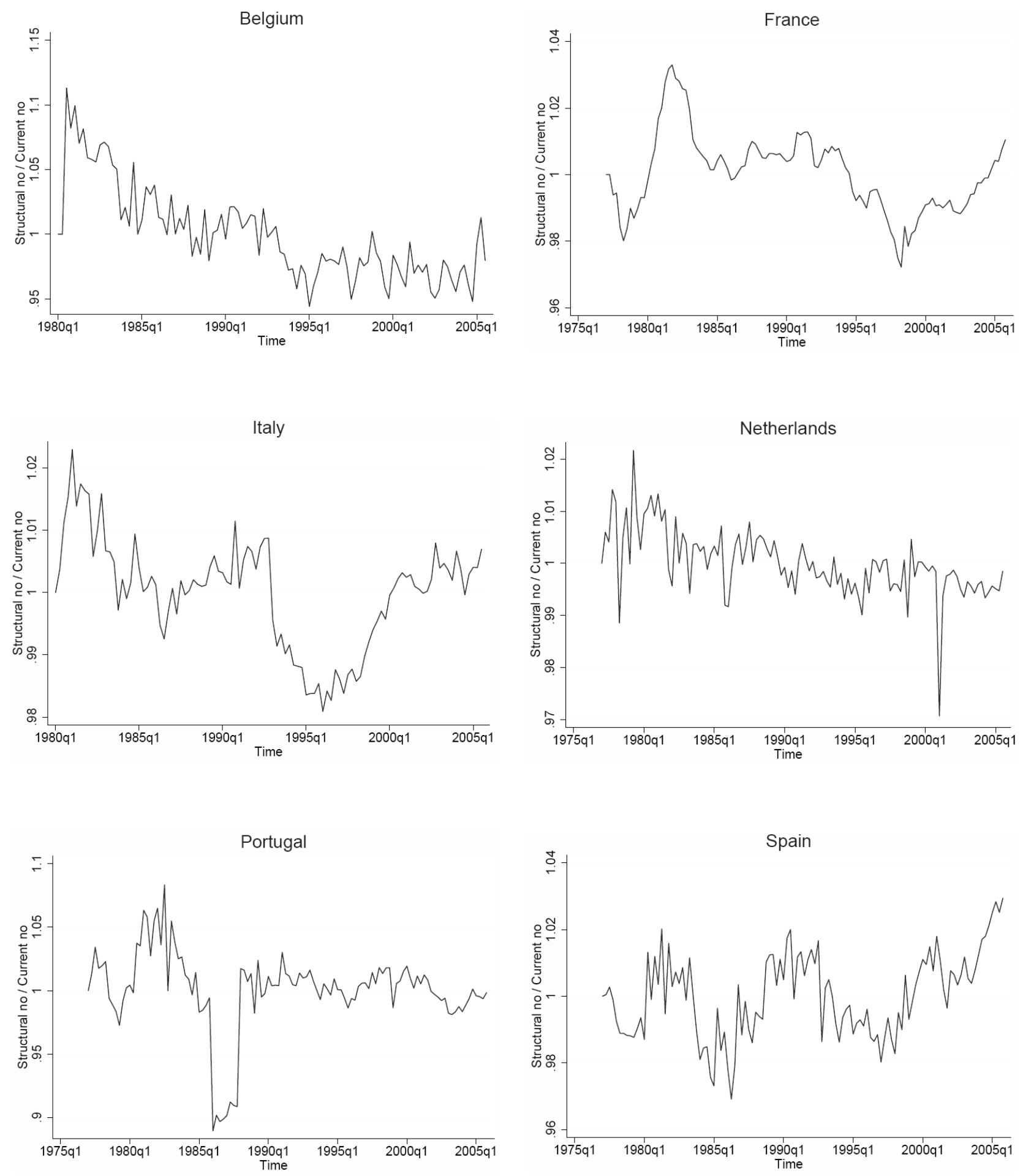


\section{Figure 6}

Predicted current account: Full sample and subsample up to 1998:q4
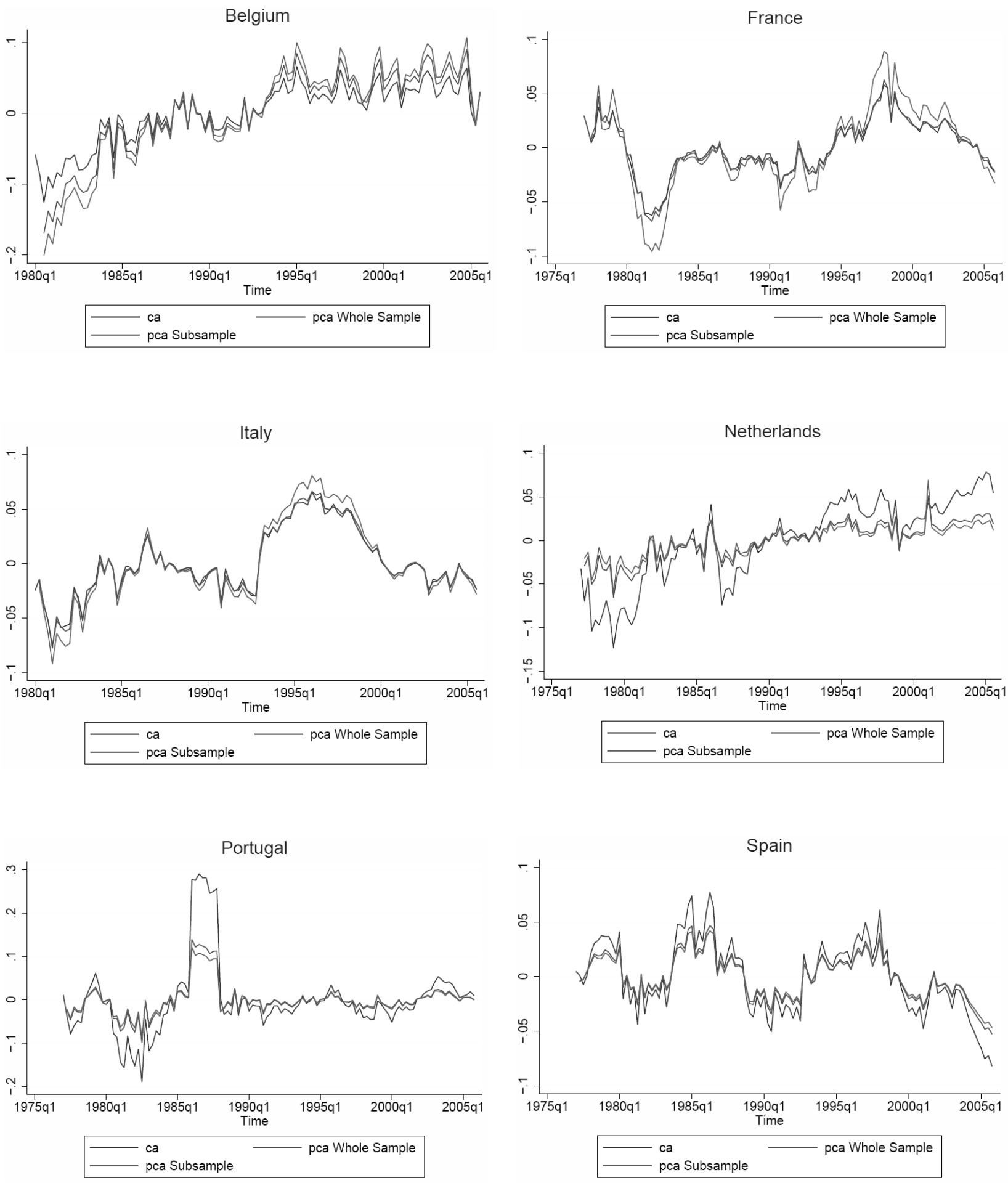


\section{Table 1}

Descriptive statistics and key parameter values

\begin{tabular}{|c|c|c|c|c|c|c|}
\hline & Belgium & France & Italy & Netherlands & Portugal & Spain \\
\hline Period & $1980 q 1-2005 q 3$ & $1977 q 1-2005 q 4$ & $1980 q 1-2005 q 3$ & $1977 q 1-2005 q 3$ & $1977 q 1-2005 q 4$ & $1977 q 1-2005 q 4$ \\
\hline$a$ & 0.34 & 0.38 & 0.40 & 0.26 & 0.42 & 0.35 \\
\hline $\boldsymbol{\beta}$ & 0.9907 & 0.9926 & 0.9909 & 0.9929 & 0.9979 & 0.9929 \\
\hline Mean $C A^{*}$ & 0.0496 & 0.0123 & 0.0280 & 0.0766 & -0.1569 & -0.0148 \\
\hline Mean Ano & 0.0048 & 0.0032 & 0.0044 & 0.0060 & 0.0052 & 0.0035 \\
\hline Mean $r$ & 0.0094 & 0.0074 & 0.0092 & 0.0071 & 0.0021 & 0.0072 \\
\hline Mean $\Delta p$ & -0.0029 & 0.0000 & 0.0011 & -0.0018 & -0.0002 & 0.0024 \\
\hline$(1-a)(1-\gamma) / \gamma$ & 1.98 & 1.86 & 1.80 & 2.22 & 1.74 & 1.95 \\
\hline \multirow[t]{2}{*}{ Mean $r$} & 0.0035 & 0.0075 & 0.0113 & 0.0032 & 0.0021 & 0.0119 \\
\hline & Austria & Finland & Germany & Ireland & & \\
\hline Period & $1977 q 1-2005 q 4$ & $1977 q 1-2005 q 4$ & $1991 q 1-2005 q 4$ & $1997 q 1-2005 q 4$ & & \\
\hline$a$ & 0.33 & 0.26 & 0.36 & 0.41 & & \\
\hline$\beta$ & 0.9937 & 0.9905 & 0.9950 & 0.9990 & & \\
\hline Mean $C A^{*}$ & 0.0485 & 0.0710 & 0.0266 & 0.2654 & & \\
\hline Mean $\Delta n o$ & 0.0049 & 0.0064 & 0.0043 & 0.0104 & & \\
\hline Mean $r$ & 0.0064 & 0.0096 & 0.0050 & 0.0010 & & \\
\hline Mean $\Delta p$ & -0.0009 & 0.0007 & 0.0003 & -0.0084 & & \\
\hline$(1-a)(1-\gamma) / \gamma$ & 2.01 & 2.22 & 1.92 & 1.77 & & \\
\hline Mean $r^{*}$ & 0.0046 & 0.0113 & 0.0050 & -0.0140 & & \\
\hline
\end{tabular}



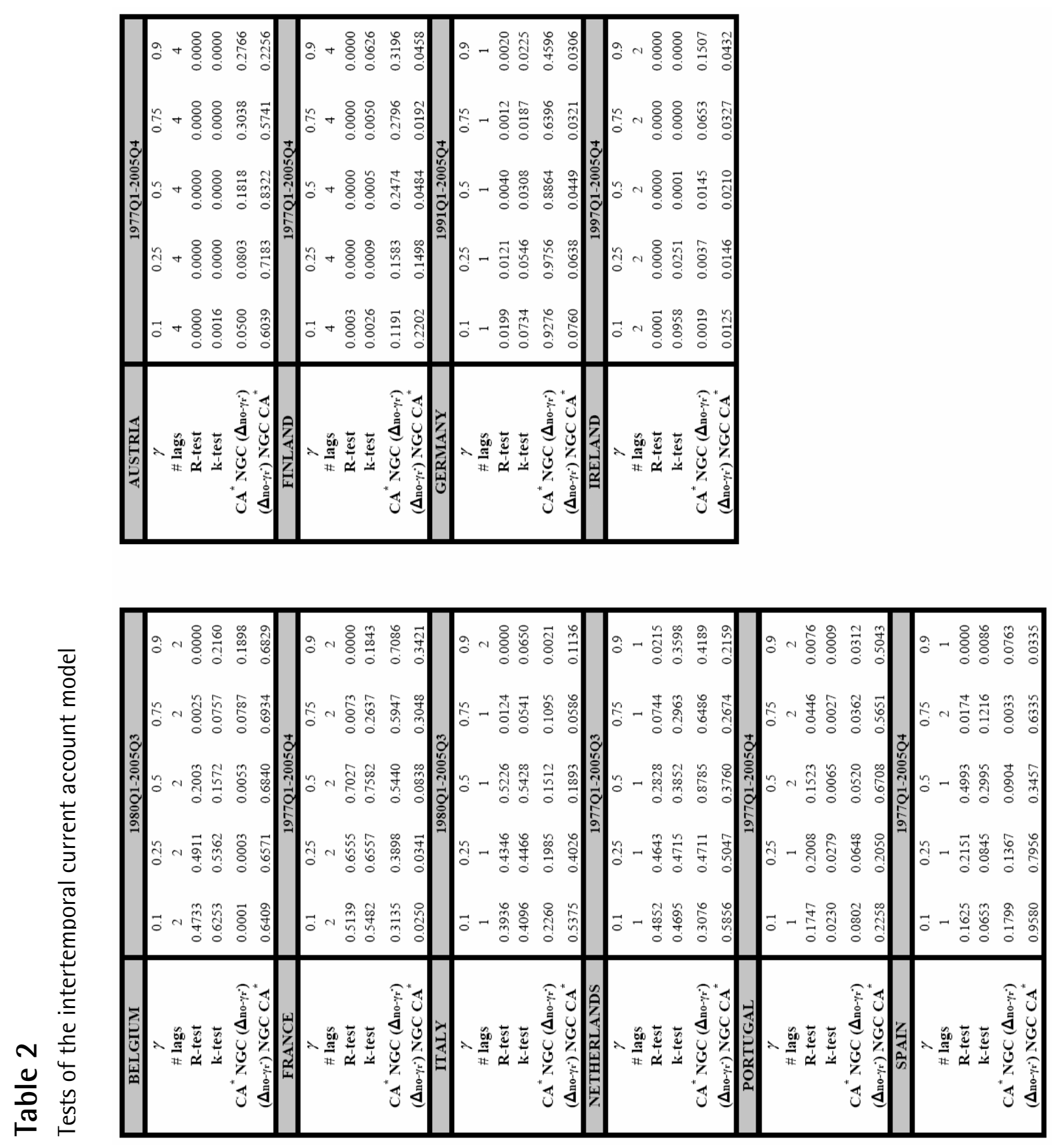


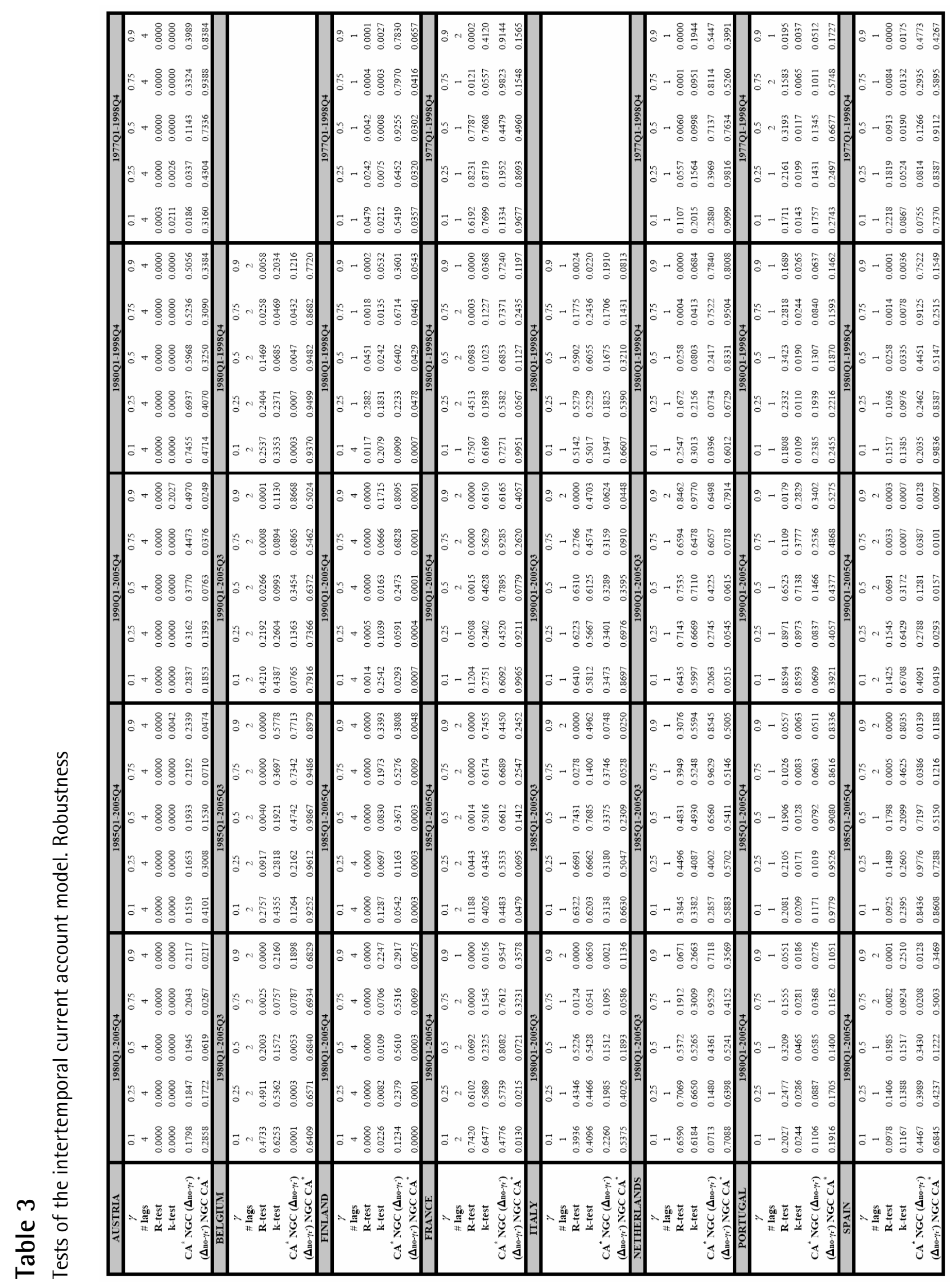

IESE Business School-University of Navarra - 33 


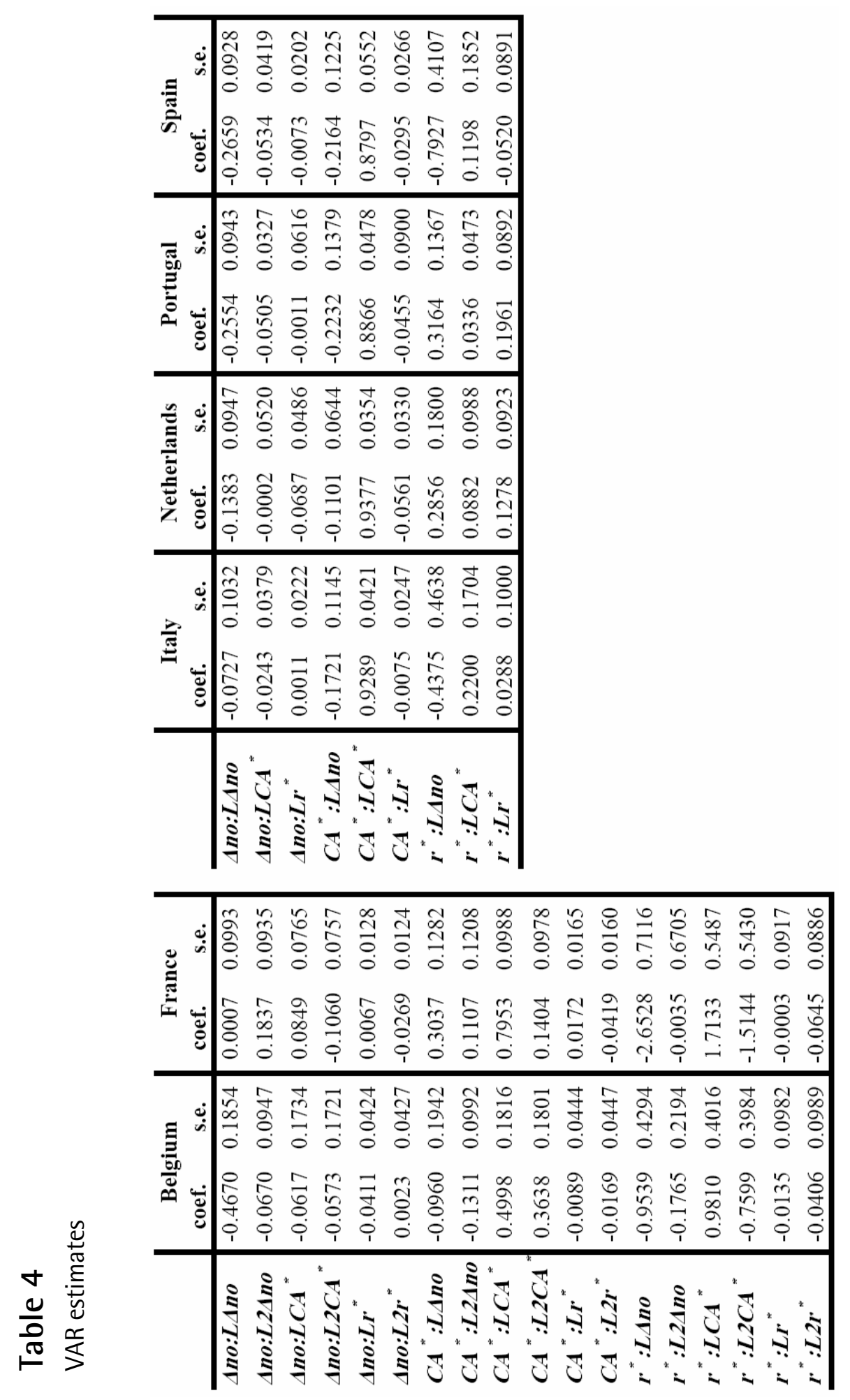




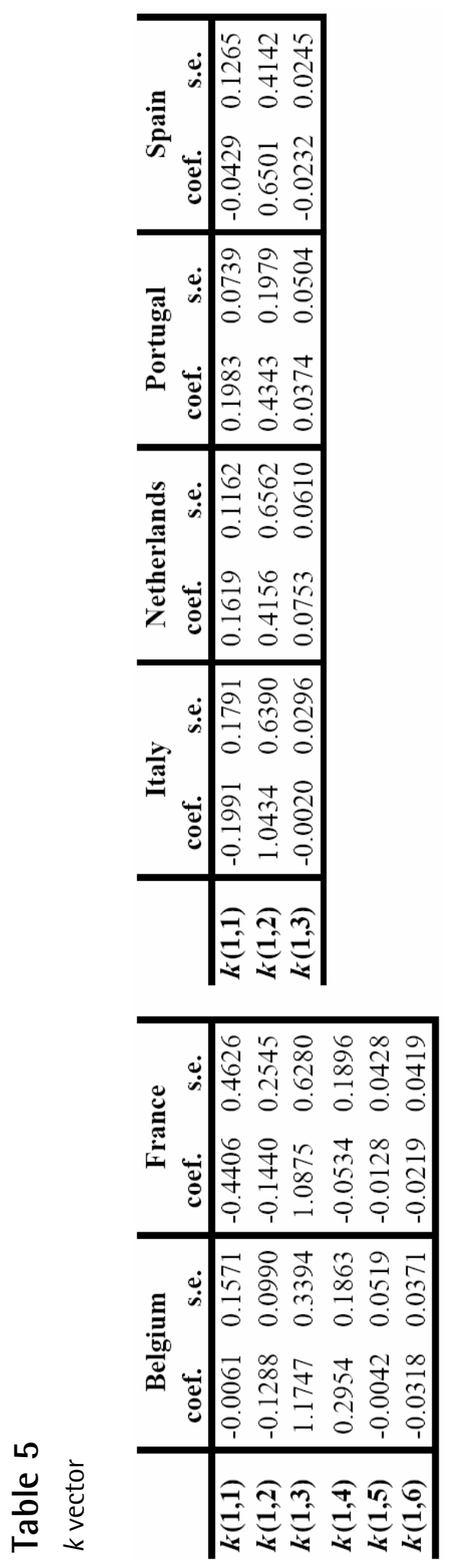




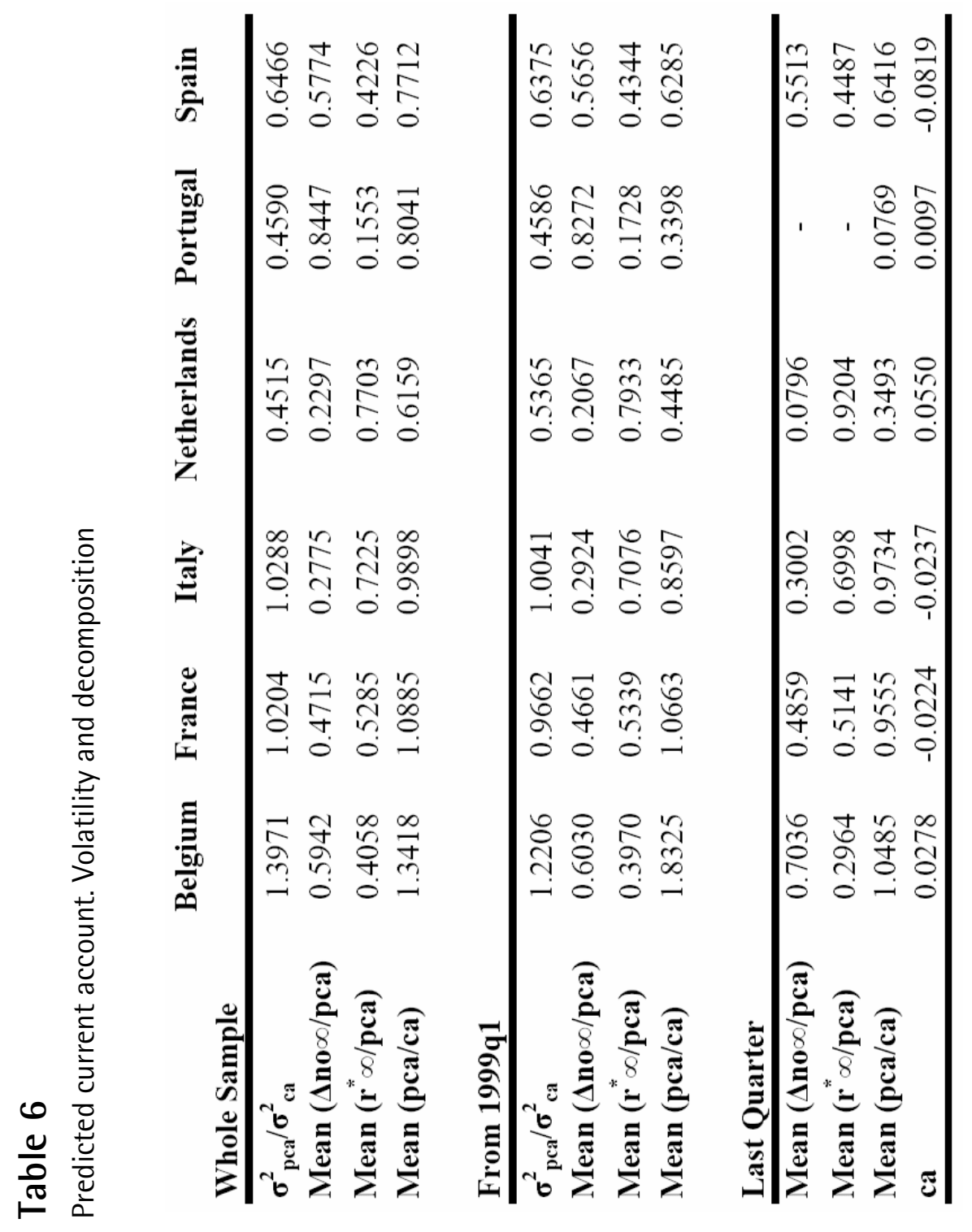




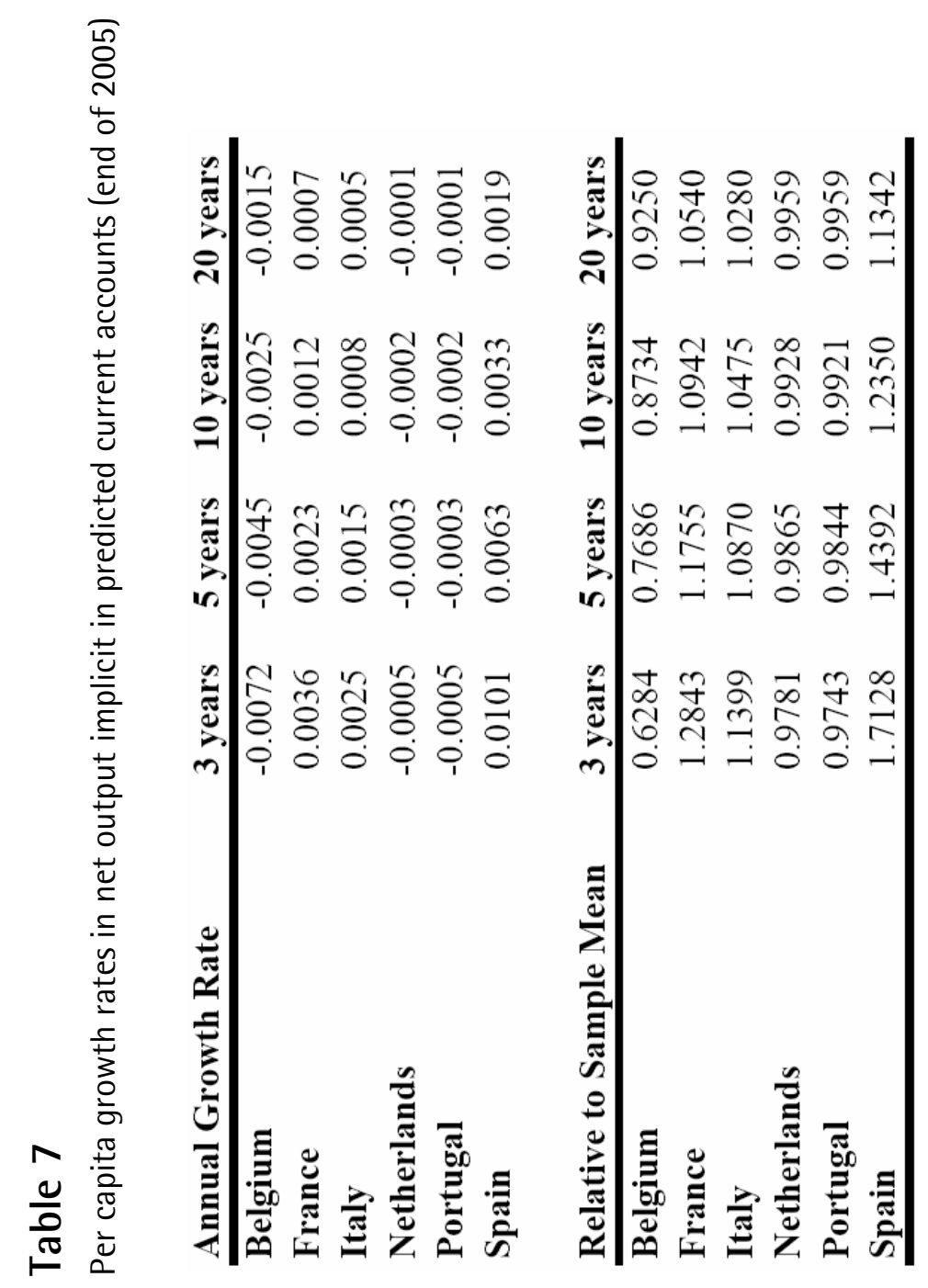

IESE Business School-University of Navarra - 37 